九州大学学術情報リポジトリ

Kyushu University Institutional Repository

加齢雌マウスの脳に蓄積する8/オキソグアニンは海 馬歯状回と大カレハ島の神経新生を障害し性的二形 性をきたす

春山，直樹

ht tps://doi. org/10.15017/4059947

出版情報：Kyushu University，2019，博士（医学），課程博士 バージョン :

権利関係: (C)2019 Elsevier Ltd. All rights reserved. 
Original Research Article

\title{
8-Oxoguanine accumulation in aged female brain impairs neurogenesis in the dentate gyrus and major island of Calleja, causing sexually dimorphic phenotypes
}

\author{
Naoki Haruyama $^{\text {a,b }}$, Kunihiko Sakumi ${ }^{\mathrm{a}}$, Atsuhisa Katogi ${ }^{\mathrm{a}}$, Daisuke Tsuchimoto ${ }^{\mathrm{a}}$, \\ Gabriele De Luca ${ }^{\mathrm{c}}$, Margherita Bignami ${ }^{\mathrm{d}}$, Yusaku Nakabeppu ${ }^{\mathrm{a}, *}$ \\ ${ }^{a}$ Division of Neurofunctional Genomics, Department of Immunobiology and Neuroscience, Medical Institute of Bioregulation, Kyushu University, 3-1-1 Maidashi, \\ Higashi-ku, Fukuoka 812-8582, Japan \\ ${ }^{\mathrm{b}}$ Department of Medicine and Clinical Science, Graduate School of Medical Sciences, Kyushu University, 3-1-1 Maidashi, Higashi-ku, Fukuoka 812-8582, Japan \\ ${ }^{\mathrm{c}}$ Department of Oncology and Molecular Medicine, Istituto Superiore di Sanità, Viale Regina Elena 299, Rome 00161, Italy \\ ${ }^{\mathrm{d}}$ Department of Environment and Health, Istituto Superiore di Sanità, Viale Regina Elena 299, Rome 00161, Italy
}

\section{A R T I C L E I N F O}

\section{Keywords:}

8-Oxoguanine

Adult neurogenesis

Major island of Calleja

Spontaneous locomotion

Cognitive impairment

Dopamine receptor D3

\begin{abstract}
A B S T R A C T
In mammals, including humans, MTH1 with 8-oxo-dGTPase and OGG1 with 8-oxoguanine DNA glycosylase minimize 8-oxoguanine accumulation in genomic DNA. We investigated age-related alterations in behavior, 8oxoguanine levels, and neurogenesis in the brains of Mth1/Ogg1-double knockout (TO-DKO), Ogg1-knockout, and human MTH1-transgenic (hMTH1-Tg) mice. Spontaneous locomotor activity was significantly decreased in wild-type mice with age, and females consistently exhibited higher locomotor activity than males. This decrease was significantly suppressed in female but not male TO-DKO mice and markedly enhanced in female hMTH1-Tg mice. Long-term memory retrieval was impaired in middle-aged female TO-DKO mice. 8-Oxoguanine accumulation significantly increased in nuclear DNA, particularly in the dentate gyrus (DG), subventricular zone (SVZ) and major island of Calleja (ICjM) in middle-aged female TO-DKO mice. In middle-aged female TO-DKO mice, neurogenesis was severely impaired in SVZ and DG, accompanied by ICjM and DG atrophy. Conversely, expression of hMTH1 efficiently suppressed 8-oxoguanine accumulation in both SVZ and DG with hypertrophy of ICjM. These findings indicate that newborn neurons from SVZ maintain ICjM in the adult brain, and increased accumulation of 8-oxoguanine in nuclear DNA of neural progenitors in females is caused by 8-oxo-dGTP incorporation during proliferation, causing depletion of neural progenitors, altered behavior, and cognitive function changes with age.
\end{abstract}

\section{Introduction}

During ontogenesis, neural progenitors divide and proliferate from the embryonic stage to the immediate postnatal stage, differentiating into neurons that lose their ability to divide and construct neural networks (Hall, 2012). Substantial energy is required to maintain basic brain function and is supplied by consuming large amounts of oxygen and glucose via oxidative phosphorylation in mitochondria (MacKenna et al., 2012). However, highly reactive oxygen species (ROS), including superoxide anions, hydrogen peroxide or hydroxyl radicals, are generated through reduction of oxygen by electrons leaked from the electron transport chains in mitochondria (Kang et al., 1999; Nunnari and Suomalainen, 2010). Reactive nitrogen species (RNS) such as nitric oxide (NO) are physiologically generated by neural excitation or during the inflammatory responses of glial cells, which are activated during infection or inflammation in the brain. In the presence of superoxide anions, which are also formed by glial cells, NO can be converted into peroxynitrite, a highly reactive species. A range of defense mechanisms minimize the toxic effects of reactive species, including antioxidant enzymes, such as superoxide dismutase (SOD), catalase and glutathione

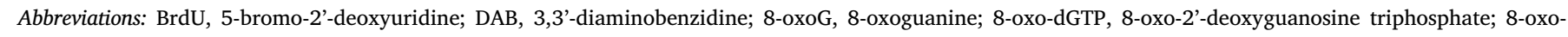

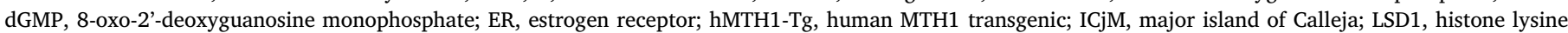

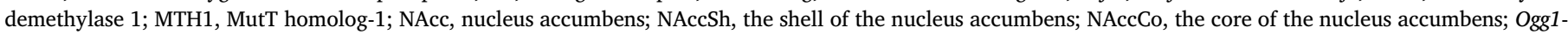
KO, Ogg1-knockout; TO-DKO, Mth1/Ogg1-double knockout; TUNEL, terminal deoxynucleotidyl transferase dUTP nick end labeling

* Corresponding author.

E-mail address: yusaku@bioreg.kyushu-u.ac.jp (Y. Nakabeppu). 
peroxidase. However, the brain is constantly exposed to endogenous reactive species produced during normal brain function (Dasuri et al., 2013).

Neurons need to survive and function throughout the life of the individual. However, postmitotic neurons are known to be lost owing to dysfunction associated with aging, particularly via oxidative stress (Dasuri et al., 2013). Consequently, several defense mechanisms function to retain neural networks, including the supply of newborn neurons from neural progenitor cells in the adult brain (Braun and Jessberger, 2014; Kempermann et al., 2018). Despite the many defense mechanisms evolved by eukaryotic cells, various oxidized lipids, proteins, carbohydrates and nucleic acids have been found to accumulate in the brains of humans and non-human animals during aging, and under pathological conditions (Cobb and Cole, 2015; Coppede and Migliore, 2015). Among all nucleobases, guanine is the most susceptible to oxidation, and is modified to 8-oxo-7,8-dihydro-guanine (8-oxoG), which is one of the major oxidized bases in the nucleotide pool or DNA, and is known to be highly accumulated in patient brains with aging-related neurodegenerative diseases, including Alzheimer's disease (AD), Parkinson's disease and Huntington's disease (Nakabeppu, 2017).

8-OxoG can pair with adenine as well as cytosine in DNA during replication, and can cause mutation or cell death if accumulated in cellular DNA (Oka et al., 2008; Ohno et al., 2014). To minimize accumulation of 8-oxoG in cellular DNA, mammals, including humans, are equipped with two enzymes, MutT homolog-1 (MTH1) and OGG1 (Nakabeppu, 2017). MTH1, a mammalian homolog of bacterial MutT, hydrolyzes 8-oxo-2'-deoxyguanosine triphosphate (8-oxo-dGTP) generated in the nucleotide pool to 8-oxo-dGMP and pyrophosphate, avoiding incorporation of 8-oxo-dGTP into cellular DNA during DNA replication. Conversely, OGG1 with 8-oxoG DNA glycosylase activity, excises 8-oxoG opposite cytosine in DNA, thus initiating base excision repair (BER) to eliminate 8-oxoG in DNA. In humans and mice, both MTH1 and OGG1 proteins are highly expressed in neurons throughout the brain, particularly in the cortex, hippocampal formation, hypothalamus and other regions. In the brains of patients with various neurodegenerative diseases, altered expression of MTH1 and OGG1 has been documented (Shimura-Miura et al., 1999; Furuta et al., 2001; Iida et al., 2002; Kikuchi et al., 2002; Fukae et al., 2005; Song et al., 2011; Leon et al., 2016), thus suggesting that MTH1 and OGG1 play important roles in maintaining neural functions by suppressing 8-oxoG accumulation in neurons. Indeed, mice deficient in MTH1 and/or OGG1 exhibit increased vulnerability to oxidative stress-induced neurodegeneration (Kajitani et al., 2006; Yamaguchi et al., 2006; Liu et al., 2011; Sheng et al., 2012; Cardozo-Pelaez et al., 2012). Moreover, it has been demonstrated that transgenic mice expressing human MTH1 (hMTH1) protein are resistant to neurodegenerative conditions with reduced accumulation of 8-oxoG in the brain (De Luca et al., 2008; Murakami et al., 2012; Ventura et al., 2013), and exhibit improved behavioral and cognitive function (De Luca et al., 2013).

The repair capacity of 8-oxoG in the human brain is thought to decline with age (Tian et al., 2009; Swain and Rao, 2012), and accumulation of 8-oxoG in the brains of non-human animals has been reported to increase during aging (Moller et al., 2010; Nie et al., 2013; Sattarova et al., 2013). We previously reported that neurons isolated from the brains of adult Mth1/Ogg1-double knockout (TO-DKO) mice exhibit impaired neuritogenesis and poor arborization, particularly in the absence of anti-oxidants accompanied by increased accumulation of 8-oxoG in mitochondrial DNA (Leon et al., 2016), suggesting TO-DKO mice may develop aging-related brain dysfunction.

In the present study, we conducted a battery of behavioral analyses of Ogg1-knockout (Ogg1-KO), TO-DKO and hMTH1-transgenic (hMTH1$\mathrm{Tg}$ ) mice, compared with wild-type mice, during aging. The results revealed that spontaneous locomotor activity in the home cage was significantly decreased in wild-type mice during aging, and female mice consistently exhibited greater locomotor activity than male mice. However, the decrease was significantly suppressed in female but not male TO-DKO mice, and was markedly enhanced in female hMTH1-Tg mice. Moreover, middle-aged female TO-DKO mice exhibited mild cognitive impairment compared with wild-type mice. Examining 8oxoG accumulation, neurogenesis, and histopathology in the mouse brain revealed that the accumulated 8-oxoG in the nuclear DNA of neural progenitors during aging of female mice is mainly caused by 8 oxo-dGTP accumulating in the nucleotide pool, which causes impaired neurogenesis in the aging brain and alters spontaneous locomotor and cognitive functions, as sexually dimorphic phenotypes.

\section{Material and methods}

\subsection{Mice}

We developed $M t h 1^{+/-}$(Tsuzuki et al., 2001) and Ogg $1^{+/-}$mice (Sakumi et al., 2003), which were backcrossed onto C57BL/6 J for more than 20 generations. First, $M$ th $1^{+/-} / \mathrm{Ogg} 1^{+/-}$mice were obtained by mating with heterozygous mice. Those $M t h 1^{+/-} / O g g 1^{+/-}$mice were then crossed with each other to obtain $M t h 1^{-/-} / O g g 1^{-1-}$ (TO-DKO) and $M$ th $1^{+/+} / O g g 1^{+/+}$(wild type) mice. Ogg $1^{-/-}$(Ogg1-KO) mice and corresponding wild-type mice were obtained by mating between heterozygous mice. TO-DKO, Ogg1-KO and wild-type controls were in-bred to yield offspring for the experiments, for only two generations except wild-type controls. The genotyping of offspring was determined by polymerase chain reaction (PCR) using tail DNA, as described previously (Leon et al., 2016). A hMTH1-Tg hemizygous mouse was previously established (De Luca et al., 2008). To determine the genotype and examine the copy number of hMTH1 cDNA in the offspring, quantitative real-time PCR was performed using tail DNA with Thunderbird qPCR kit (Toyobo, Osaka, Japan) and a Thermal Cycler Dice Real Time System Single (Takara Bio, Shiga, Japan). The primer pairs were as follows: hMTH1: forward; 5'-TTGAGTTCGTGGGCGAGC-3' and reverse; 5'-GCATGGGCGCATTTCG-3', RNaseP (for housekeeping gene): forward; 5'-GCCGGAGCTTGGAACAGA-3' and reverse; 5'-GGT GCCTCACCTCAGCCAT-3'. The reactions were performed in triplicate and the relative standard curve method was used to calculate relative values. Young ( $8.5 \pm 0.1$ weeks of age), middle-aged ( $33.7 \pm 0.1$ weeks of age), and old ( $82.3 \pm 0.3$ weeks of age) mice of both sexes were transferred to the behavior analysis room. After performing behavior analysis, mice were used for pathological analyses. For experiments with injection of 5-bromo-2'-deoxyuridine (BrdU) and dopamine receptor D1 (DRD1) antagonist, we used female mice aged $55 \pm 1$ and $58 \pm 2$ weeks, respectively. Mice with any tumor identified macroscopically in the visceral organs during brain dissection were excluded from analysis. Mice were maintained in an air-conditioned specificpathogen-free room at $22^{\circ} \mathrm{C}$ with a 12:12-h light and dark cycle (lights on 08:00, off at 20:00), and given ad libitum access to food and water. All behavior analyses, except continuous measurement of spontaneous locomotor activity, were performed from 12:00 to 20:00.

\subsection{Spontaneous locomotor activity}

Mice were individually housed for at least 1 week before monitoring spontaneous locomotor activity in the home cage $(27 \times 14 \times 15 \mathrm{~cm})$. The locomotor activity was measured as a count of infrared-beam break using an infrared beam sensor (NS-AS01; Neuroscience Inc., Japan) for 3 days, and analyzed with DAS-008 software, as described previously (Sheng et al., 2012).

\subsection{Morris water maze}

The water maze consisted of a circular pool with diameter of $100 \mathrm{~cm}$ and a $30 \mathrm{~cm}$ depth, filled to depth of $15 \mathrm{~cm}$ with room-temperature tap water $\left(22^{\circ} \mathrm{C}\right)$. Several visual cues were placed on the interior of the pool. Performance was scored using a video tracking system, WaterMaze (Actimetrics Inc., Evanston, UK). To evaluate spatial 
working memory, mice were trained to escape onto a 15-cm diameter, circular, clear, Plexiglas platform submerged $1 \mathrm{~cm}$ beneath the surface of the water that was invisible to the mice while swimming. Mice were given four consecutive trials per day for 6 (male) or 7 (female) days, 2 weeks after the last BrdU injection. Initial latency to escape onto the platform and total swimming distance were measured. To evaluate memory retrieval, a probe test was conducted in the pool without the platform for $60 \mathrm{~s}, 1.5$ and $24 \mathrm{~h}$ after the last acquisition trial. The parameters measured during the probe test were as follows: [1] initial latency to reach the virtual platform location, [2] time spent in target quadrant during the test period, and [3] number of crossings of the virtual platform.

\subsection{Novel object recognition test}

The novel object recognition test was performed as described previously (Bevins and Besheer, 2006). The open field box $(50 \times 50 \times 40 \mathrm{~cm}$, white) was placed in a dark room illuminated by a dim light $(50 \mathrm{~lx})$. The day before the test (Day 0), each middle-aged female mouse was habituated in the apparatus for $15 \mathrm{~min}$. On the next day (Day 1), the mouse was allowed to explore the two identical objects (animal mascot, Lego blocks) placed in the arena for $10 \mathrm{~min}$ (experiment for short term retrieval) or $15 \mathrm{~min}$ (experiment for long term retrieval) as sample object exposure. Each object was placed in a symmetrical position within the box, at the same distance $(12 \mathrm{~cm})$ from the side wall, and separated by $20 \mathrm{~cm}$. For novel object recognition, 1.5 or $16 \mathrm{~h}$ after the sample object exposure, the mouse was exposed to two different objects, one of the sample objects as a familiar object and the novel object, placed within the arena, for $10 \mathrm{~min}$ (short term retrieval) or $15 \mathrm{~min}$ (long term retrieval). The time spent exploring each object was determined and calculated as the preference index: Time ${ }^{\text {novel }} /$ (Time $^{\text {novel }}+$ Time $^{\text {familiar }}$ ).

\subsection{Other behavioral analyses}

Methods for the open field test, elevated plus maze, light and dark transition box test and rotarod test are described in the Supplementary material.

\subsection{Brain sample preparation}

After the final behavioral analysis, the mouse was anesthetized with a combination of medetomidine $(0.3 \mathrm{mg} / \mathrm{kg})$, midazolam $(4.0 \mathrm{mg} / \mathrm{kg})$, and butorphanol $(5.0 \mathrm{mg} / \mathrm{kg})$, then perfused transcardially with $20 \mathrm{~mL}$ of saline and $1 \mathrm{~mL} / \mathrm{g}$ of $4 \%$ paraformaldehyde in $1 \times$ phosphate buffered saline (PBS). The brain was removed, post-fixed with $4 \%$ paraformaldehyde at $4{ }^{\circ} \mathrm{C}$ for $24 \mathrm{~h}$, then cryoprotected in $20 \%$ and $30 \%$ sucrose in $1 \times \mathrm{PBS}$ at $4^{\circ} \mathrm{C}$ for $24 \mathrm{~h}$ each. For immunostaining of dopamine D3 receptor (DRD3), the brain was post-fixed in $4 \%$ paraformaldehyde for $1 \mathrm{~h}$ at room temperature before cryoprotection. Sagittal or coronal blocks were prepared using a Mouse Brain Slicer (MK-MC-01, Muromachi Kikai Co., Ltd., Tokyo, Japan), mounted in FSC 22 Frozen Section Media (Leica Microsystems K.K., Tokyo, Japan, frozen in liquid nitrogen and stored at $-80^{\circ} \mathrm{C}$ until use. Brain blocks were cut on a cryostat at a thickness of $40 \mu \mathrm{m}$ and collected as free-floating sections in PBS.

\subsection{Primary antibodies}

Mouse anti-8-oxo-dG (NS45.1, Japan Institute for the Control of Aging, Nikken Seil Co., Ltd., Fukuroi, Shizuoka, Japan), mouse antiFOSB antibody (1:500, 5G4, Cell Signaling Technology), mouse antiBrdU antibody (1:800, Roche), rabbit anti-NeuN antibody (1:1000, ABN-78, Millipore), rabbit anti-GAD67 antibody (1:150, sc-5602, Santa Cruz), goat anti-doublecortin (DCX) antibody (1:200, sc-8066, Santa Cruz), goat anti-SOX2 antibody (1:250, sc-17320, Santa Cruz), rabbit
anti-DRD3 antibody (1:100, ab42114, Abcam), and mouse anti-calretinin antibody (1:2000, clone 6B8.2, MAB1568, Millipore) were used as the primary antibodies for immunohistochemistry and immunofluorescence.

\subsection{Immunohistochemistry}

Immunohistochemical analyses were performed as described previously (Yamaguchi et al., 2006). The prepared free-floating sections were processed immediately for immunohistochemistry (IHC), with an appropriate pretreatment and reaction with a primary antibody, then processed using a Vector $\mathrm{ABC}$ kit (Vector Laboratories, Burlingame, CA, USA) with the proper biotinylated secondary antibody. The 3,3'diaminobenzidine $(\mathrm{DAB}) /$ nickel (Vector Laboratories) reaction was then used to visualize the bound secondary antibody. Digital images were acquired using an AxioImager microscope, equipped with an AxioCam 503 color CCD camera. Axiovision SE64 imaging software (Carl Zeiss Microscopy, Tokyo, Japan) was used.

\subsection{Quantitative immunodetection of 8-oxoguanine in DNA}

For immunodetection of 8-oxoG in mitochondrial or nuclear DNA, the free-floating sections were pretreated as described previously (Yamaguchi et al., 2006). Briefly, to detect 8-oxoG in the mitochondrial DNA, sections were pretreated only with RNase $(5 \mathrm{mg} / \mathrm{ml}$; Sigma-Aldrich Japan, Tokyo, Japan) and were directly subjected to IHC with the anti-8-oxo-dG antibody. To detect 8-oxoG in nuclear DNA, RNasetreated sections were further pretreated with $2 \mathrm{~N} \mathrm{HCl}$ to denature the nuclear DNA. These pretreated sections were subjected to IHC with an anti-8-oxo-dG antibody. Digital images of 8-oxo-dG IHC were converted to gray scale, then the signal intensity of 8-oxo-dG immunoreactivity was quantified using ImageJ 1.80 (NIH, Bethesda, MD, USA). The region of interest was defined manually, and integrated pixel densities were determined using a fixed threshold for each experiment with reference to the results of negative control sections (e.g., minimum displayed value, 0 ; maximum displayed value, 100 for detection of signal 8-oxo-dG in nucleus) to obtain the 8-oxoG index.

\subsection{Laser-scanning confocal immunofluorescence microscopy}

The free-floating sections were incubated with appropriate primary antibodies diluted in 10\% Block Ace (Dainippon Pharmaceutical, Osaka, Japan) at $4{ }^{\circ} \mathrm{C}$ overnight. The sections were incubated with appropriate Alexa Fluor-labeled secondary antibodies (Thermo Fisher Scientific K.K, Tokyo, Japan) at RT for $45 \mathrm{~min}$. To quench autofluorescence derived from lipofuscin, the sections were incubated with $0.3 \%$ of Sudan Black B in $50 \%$ ethanol at room temperature for $45 \mathrm{~min}$. Digitized images were captured using a laser scanning confocal microscope system (LSM 700, Carl Zeiss Microscopy) attached to an inverted microscope (Axio Observer Z1). Z-series of 25 optical sections of $1 \mu \mathrm{m}$ were converted into a single image using maximum intensity projection.

\subsection{BrdU labeling and stereology}

To identify proliferating cells in brains of middle-aged and female mice, BrdU ( $50 \mathrm{mg} / \mathrm{kg} /$ day, Sigma-Aldrich Japan) was intraperitoneally injected once a day for 5 consecutive days. Either $24 \mathrm{~h}$ or 28 days after the last injection, brain samples were prepared, as described above. To detect BrdU-labeled cells, the free-floating sections were pretreated as previously described (Kajitani et al., 2009; Chikama et al., 2017), then subjected to multiple immunofluorescence labeling for BrdU together with NeuN, DCX, DRD3 or calretinin. BrdU-labeled cells in subventricular zone (SVZ) adjacent to the accumbens (NAcc) or in the shell of the NAcc (NAccSh) and the major island of Calleja (ICjM) of brains dissected $24 \mathrm{~h}$ or 28 days after the last injection of BrdU, respectively, 

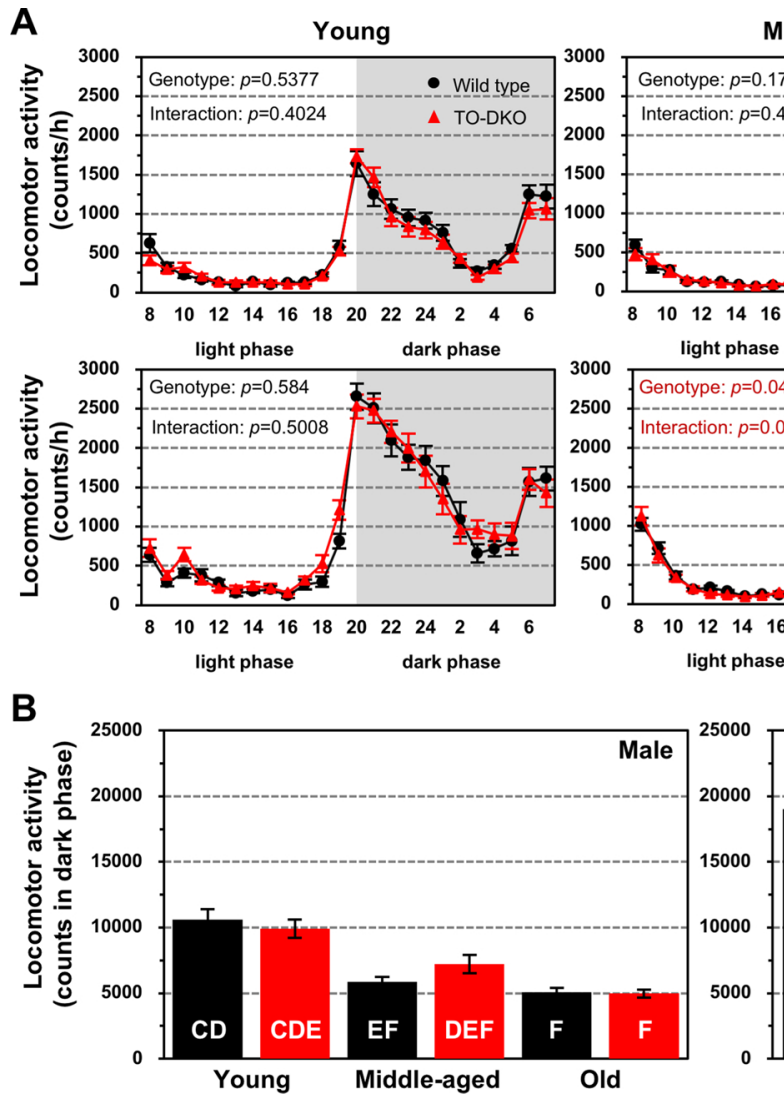

Middle-aged

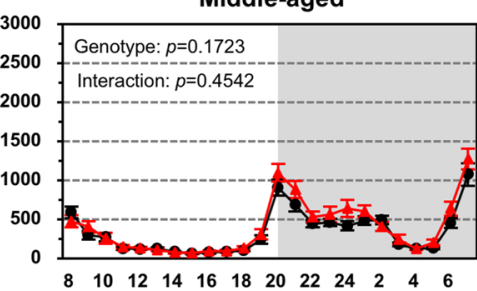

light phase

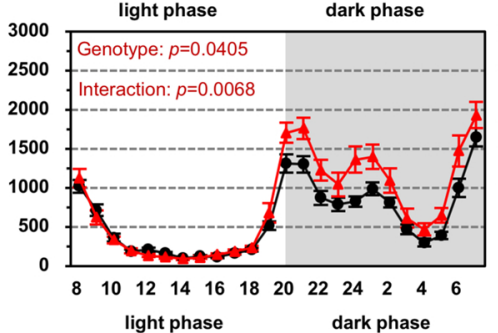

Old

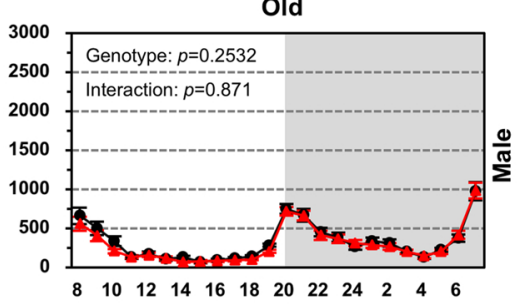

light phase dark phase

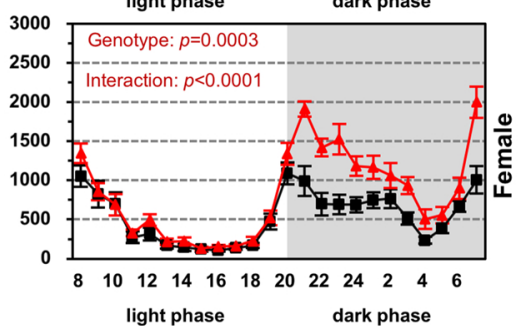

Fig. 1. Age-dependent alteration of spontaneous locomotor activity by MTH1/OGG1-double deficiency.

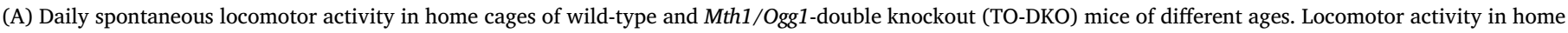

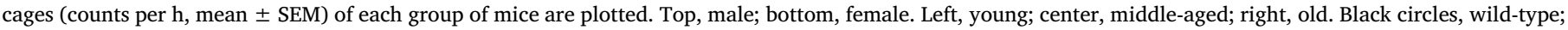

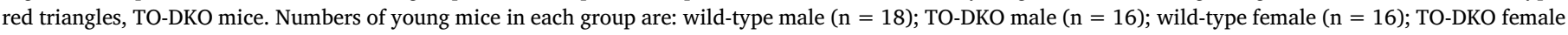

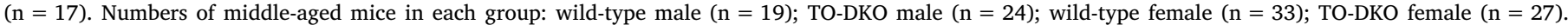

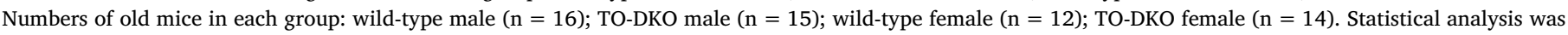

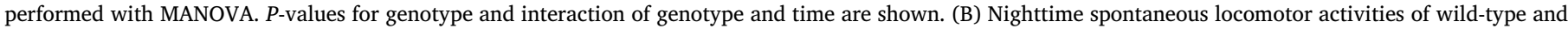

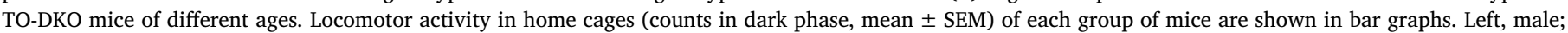

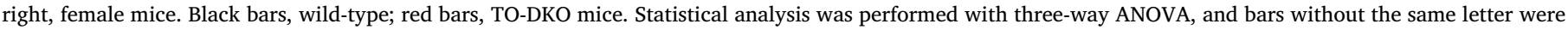
significantly different in a post-hoc Tukey-Kramer HSD test.

were counted in every second coronal section, $40 \mu \mathrm{m}$ apart (SVZ: bregma from +0.745 to $+1.245 \mathrm{~mm}$, eight sections, wild type $[\mathrm{n}=5]$, TO-DKO [n = 7]; NAccSh + ICjM: bregma from +0.745 to +1.245 $\mathrm{mm}$; eight sections, wild type $[\mathrm{n}=4]$, TO-DKO $[\mathrm{n}=4]$, Supplementary Figure S12D), using a semiautomatic stereology system (Stereoinvestigator, MBF Bioscience, Williston, VT, USA). BrdU-labeled cells in dentate gyrus (DG) of brains dissected $24 \mathrm{~h}$ after the last injection of BrdU were also counted in every fourth coronal section, $120 \mu \mathrm{m}$ apart (bregma from -1.355 to $-3.38 \mathrm{~mm}$; 11 sections, wild type [n=4], TO-DKO [ $\mathrm{n}=4]$ ), using the semiautomatic stereology system. The total number of BrdU-labeled cells in each brain region was estimated using an optical fractionator. The height of the optical disector was $21 \mu \mathrm{m}$, and the guard zone was $1.5 \mu \mathrm{m}$. The thickness of the sections was manually measured at every fifth counting frame. Total volume of SVZ, DG, and NAccSh including ICjM was estimated using Cavalieri's principle. The total number of NeuN-positive neurons in ICjM and its volume were also stereologically estimated using every second coronal section of the forebrain (bregma from +0.845 to $+1.245 \mathrm{~mm}$, seven to 10 sections) with an optical fractionator.

\subsection{Terminal deoxynucleotidyl transferase dUTP nick end labeling (TUNEL) staining}

Apoptotic cells in ventral SVZ adjacent to NAcc were detected by standard TUNEL staining using the TACS2 TdT-DAB In Situ Apoptosis
Detection Kit (Trevigen, Gaithersburg, MD, USA). Twenty-micrometerthick coronal sections of forebrain containing NAcc and ICjM (bregma from +0.745 to $+0.1045 \mathrm{~mm}$ ) were prepared, and every fourth section (three sections per sample, number of mice in each genotype: $n=4$ ) was subjected to TUNEL staining, according to the manufacturer's instructions. The labeled sections were incubated with horseradish peroxidase-Streptavidin at $37^{\circ} \mathrm{C}$ for $10 \mathrm{~min}$ and reacted with DAB solution for $5 \mathrm{~min}$. Nuclei were counterstained with methyl green. The area of SVZ adjacent to NAcc in both hemispheres was measured using ImageJ 1.80. The TUNEL-positive cells were then manually counted to estimate the density.

\subsection{Statistics}

All values are expressed as mean \pm standard error of the mean (SEM). Statistical significance was assessed using JMP Pro 12.2 (SAS Institute Japan Ltd., Tokyo, Japan). The Wilcoxon test was used as a non-parametric method, and Student's $t$-test were used as a parametric method. For comparisons between genotypes, age, and sex, three-way ANOVA and two-way multiple ANOVA were used. When significant interactions were detected, post hoc multiple comparisons were performed with the Tukey-Kramer HSD test and Student's $t$-test. Differences in continuous locomotor activity and training for acquisition in the Morris water maze between genotypes were examined using repeated measures ANOVA. $P$-values of $<0.05$ were considered 
statistically significant.

\subsection{Study approval}

All animal experimental procedures were conducted with the approval of the ethics committee for animal research at Kyushu University (Approval numbers: A26-011-2, A29-116-0).

\section{Results}

3.1. MTH1/OGG1-double deficiency suppresses the age-dependent decline of spontaneous locomotor activity only in female mice

Daily monitoring of spontaneous locomotor activity of young, middle-aged and old wild-type mice in the home cage revealed that activity in the dark phase declined significantly during aging, and female mice consistently exhibited almost twice as much activity as male mice (Fig. 1). Male TO-DKO mice exhibited the same levels of spontaneous locomotor activity in the dark phase compared with male wildtype mice at young age, and a similar degree of decline during aging. Although young female TO-DKO mice showed the same level of activity as young female wild-type mice, middle-aged and old female TO-DKO mice exhibited significantly more spontaneous locomotor activity than the corresponding wild-type female mice (Fig. 1). Middle-aged TOheterozygous mice of both sexes exhibited intermediate levels of spontaneous locomotor activity between wild-type and TO-DKO mice, suggesting hetero-insufficiency of MTH1/OGG1 (Supplementary Figure S1). As shown in Supplementary Figure S2, young, middle-aged, and old TO-DKO mice of both sexes showed no difference in body weight compared with the corresponding wild-type mice, confirming that the observed behavioral changes in female TO-DKO mice were independent of body weight.

In wild-type and TO-DKO mice of both sexes, total distance and amount of rearing in the open field test tended to slightly decrease during aging, with no significant differences between genotypes or sexes (Supplementary Figure S3A and B), indicating that wild-type and TO-DKO mice of both sexes maintained essentially the same basic locomotor function during aging. Moreover, there were no significant differences between genotypes, sexes or ages in terms of the time spent in the center of the open field apparatus (Supplementary Figure S3C). We also conducted the elevated plus maze test, light and dark transition box test, and rotarod test with middle-aged mice (Supplementary Figure S4). Middle-aged TO-DKO mice of both sexes showed no differences in the elevated plus maze, light and dark transition test and rotarod test, compared with the corresponding wild-type mice. These results indicate that TO-DKO mice did not exhibit anxiety-related behaviors or motor deficits.

Importantly, we found that the spontaneous locomotor activity in the home cage was not altered by OGG1 deficiency in middle-aged and old mice of both sexes, compared with the corresponding wild-type mice (Supplementary Figure S5).

\subsection{Transgenic expression of human MTH1 accelerates the decline of spontaneous locomotor activity during aging}

Next, we examined the effects of transgenic expression of human MTH1 on locomotor activity. In the home cage, middle-aged and old female but not male hMTH1-Tg mice exhibited much less locomotor activity in the dark phase compared with the corresponding wild-type female mice (Fig. 2).

As shown in Supplementary Figure S6A and B, middle-aged and old hMTH1-Tg mice of both sexes showed no differences in body weight compared with the corresponding wild-type mice, confirming that the observed behavioral changes in female hMTH1-Tg mice were independent of body weight. Wild-type and hMTH1-Tg mice of both sexes exhibited similar levels of total distance and amount of rearing in the open field test during aging (Supplementary Figure S6C and D), indicating that transgenic expression of hMTH1 did not alter basic locomotor functions during aging. In addition, there were no significant differences between genotypes, sexes or ages in terms of the time spent in the center of the open field apparatus (Supplementary Figure S6E).

\subsection{MTH1/OGG1-double deficiency impairs long-term memory during aging only in female mice}

To examine whether MTH1/OGG1-double deficiency affects the cognitive function of mice during aging, we conducted the Morris water maze (MWM) and novel object recognition tests using young and middle-aged wild-type and TO-DKO mice of both sexes. Spatial working memory testing in the MWM revealed no significant differences in performance between wild-type and TO-DKO mice of both sexes, regardless of age (Fig. 3A, Supplementary Figure S7 left panels). Memory retrieval testing in the MWM revealed that both middle-aged and young TO-DKO mice of both sexes exhibited no differences in short-term $(1.5 \mathrm{~h}$ after the last trial) memory retrieval compared with the corresponding wild type mice (Fig. 3B, Supplementary Figure S7 right panels). However, we found that middle-aged female TO-DKO mice exhibited significantly impaired long-term memory retrieval ( $24 \mathrm{~h}$ after the last acquisition) (Fig. 3B). Moreover, the novel object recognition test also confirmed that middle-aged TO-DKO female mice exhibited a significant impairment in long-term memory ( $16 \mathrm{~h}$ after the sample object exposure) (Fig. 3C).

\subsection{MTH1/OGG1-double deficiency increases nuclear 8-oxoguanine levels in the olfactory bulb, dentate gyrus, and ventral striatum}

Next, we compared levels of 8-oxoG accumulation in the brains of wild-type and TO-DKO female mice during aging. As shown in Fig. 4A, strong immunoreactivity of nuclear 8-oxoG was evident in the olfactory bulb, DG and SVZ, where postnatal and adult neurogenesis occur, and in young and middle-aged TO-DKO mice, compared with wild-type mice. In addition, the NAcc, especially the NAccSh containing the ICjM, and to a lesser extent NAccCo in middle-aged female TO-DKO brains also exhibited substantially increased immunoreactivity of nuclear 8oxoG (Fig. 4B). These levels were decreased in middle-aged female hMTH1-Tg brains (Fig. 4C). In contrast, no apparent difference of 8oxoG immunoreactivity was detected in mitochondrial DNA between middle-aged wild-type and TO-DKO female brains (Supplementary Figure S8A). Immunofluorescence microscopy confirmed that the 8oxoG immunofluorescence signal in mitochondrial DNA was only marginally detectable in the brains of middle-aged female TO-DKO mice (Supplementary Figure S8B). 8-OxoG immunofluorescence signals in mitochondrial DNA and cytoplasmic RNA were also only marginally detectable in the brains of old female TO-DKO mice (Supplementary Figure S8C).

Quantification of 8-oxoG immunoreactivity in NAcc, including NAccSh, with ICjM and NAccCo revealed that levels of nuclear but not mitochondrial 8-oxoG in NAcc were significantly increased in middleaged TO-DKO mice and decreased in female hMTH1-Tg mice, compared with corresponding wild-type mice (Fig. 4D, Supplementary Figure S9). As shown in Fig. 4E, levels of nuclear 8-oxoG in ICjM and NAccSh were most markedly affected by MTH1/OGG1-double deficiency or by transgenic expression of hMTH1. Laser scanning confocal immunofluorescence microscopy revealed that nuclear 8-oxoG was highly accumulated in GAD67-positive GABAergic neurons in middle-aged female TO-DKO ICjM and NAccSh (Fig. 4F). Levels of nuclear 8-oxoG in other brain regions, such as the midbrain, including the ventral tegmental area (VTA), substantia nigra, and prefrontal cortex, were not significantly different between TO-DKO and wild-type brains (Supplementary Figure S10).

These results indicate that nuclear 8-oxoG predominantly accumulates in the GABAergic neurons of the NAcc and ICjM in the female 

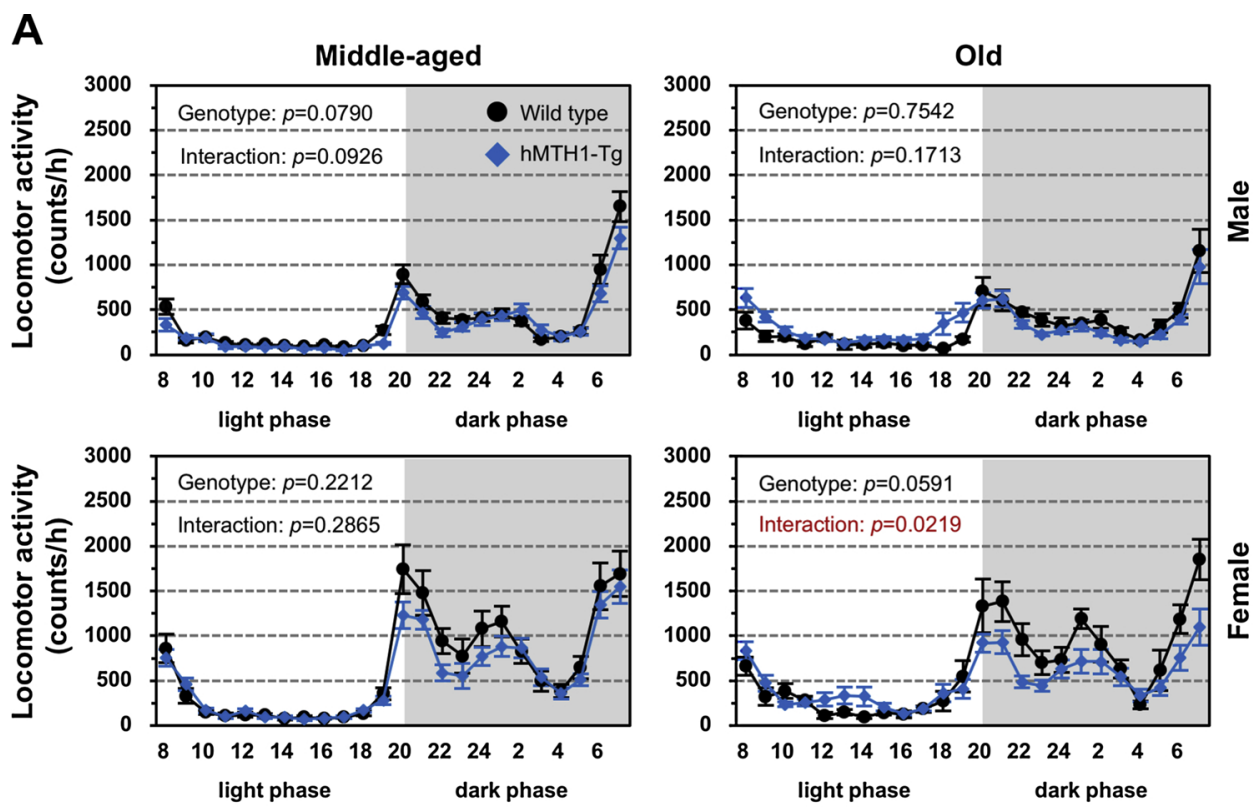

B
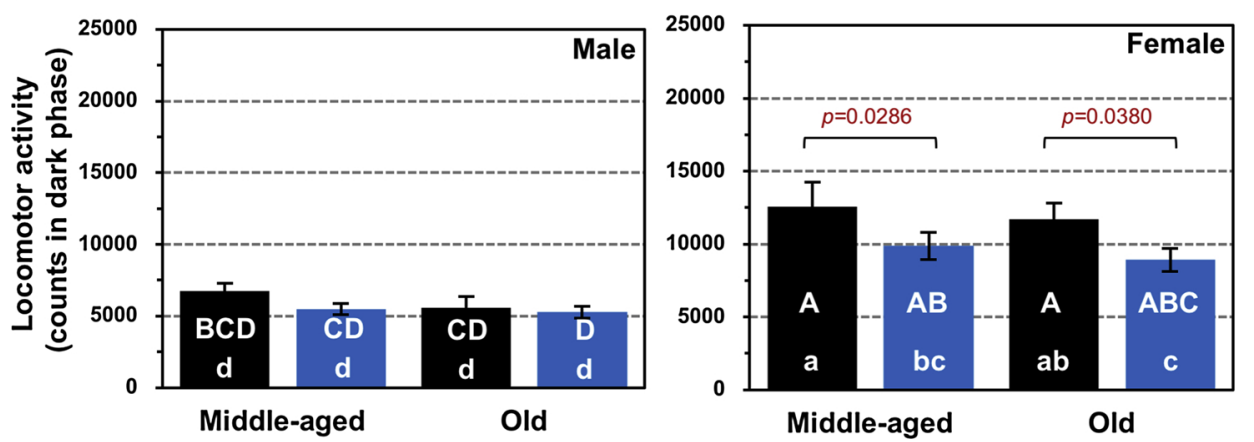

Wild type

hMTH1-Tg

3-way ANOVA

Age: $p=0.2053$

Genotype: $p=0.0051$

Sex: $p<0.0001$

Genotype•Age: $p=0.7395$

Sex-Age: $p=0.8593$

Sex $\cdot$ Genotype: $p=0.1167$

Sex $\cdot$ Genotype $\cdot$ Age: $p=0.6669$

Fig. 2. Age-dependent alteration of spontaneous locomotor activity by transgenic expression of human MTH1.

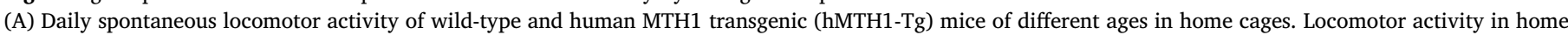

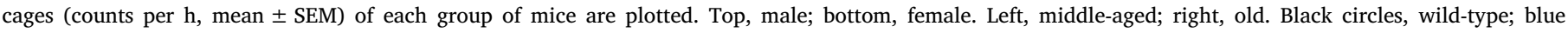

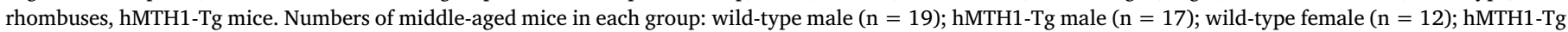

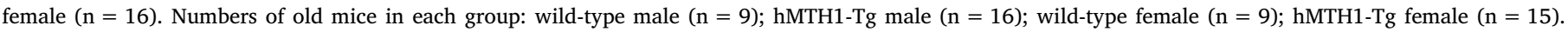

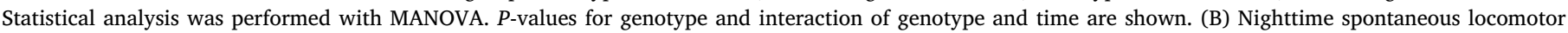

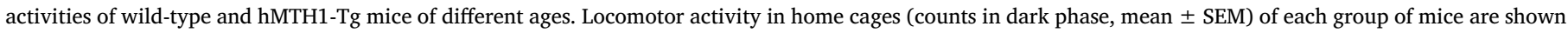

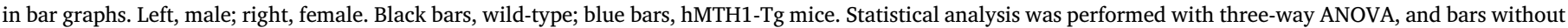

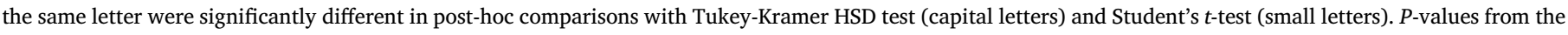
post-hoc Student's t-test are shown.

TO-DKO mouse brain during aging. In addition, these findings indicate that 8-oxoG is efficiently suppressed by transgenic expression of hMTH1, suggesting that oxidation of a free nucleotide, dGTP, rather than direct oxidation of guanine in DNA is responsible for the nuclear 8oxoG accumulation in ICjM and NAccSh, as well as the increased spontaneous locomotor activity in aged female TO-DKO mice.

Consistent with the behavioral results, we found no significant difference in nuclear 8-oxoG levels between middle-aged male TO-DKO and wild-type mouse brains (Supplementary Figure S11). Thus, only female brains were examined further.

\subsection{8-Oxoguanine accumulates in the nuclei of immature and migrating neurons in ventral SVZ, NAccSh, and ICjM in TO-DKO brains}

In adult rodent brains, it has been shown that a small number of newborn neurons originating in the adult SVZ migrate to the ventral striatum, such as the NAcc including the ICjM (Dayer et al., 2005; Shapiro et al., 2009), as well as to the olfactory bulb. Since 8-oxo-dGTP can be incorporated into nuclear DNA during proliferation of neural progenitors, we examined the levels of nuclear 8-oxoG accumulated in neural progenitors and newborn neurons migrating to the ventral striatum from the ventral SVZ in middle-aged female wild-type and TODKO mouse brains (Fig. 5).

In the TO-DKO mouse brain, 8-oxoG accumulated in the nuclei of Sox2- or DCX-positive neural progenitor cells located in SVZ, but was only marginally detectable in the corresponding region of the wild-type brain (Fig. 5A and B). In addition, we observed migrating DCX-positive cells outside the SVZ, which also accumulated higher levels of nuclear 8-oxoG (Fig. 5B, Supplementary Figure S12A). In addition, DCX/NeuNdouble positive immature neurons were also detected in the NAccSh and ICjM in the middle-aged female mouse brain, and the ICjM in the TO-DKO brain exhibited significantly higher levels of nuclear 8-oxoG compared with the wild type mouse brain (Fig. 5C and D).

These results indicate that newborn neurons from either SVZ or local progenitors, if any, were present in the NAcc, particularly in the ICjM, even in the middle-aged mouse brain. Such immature neurons 
A

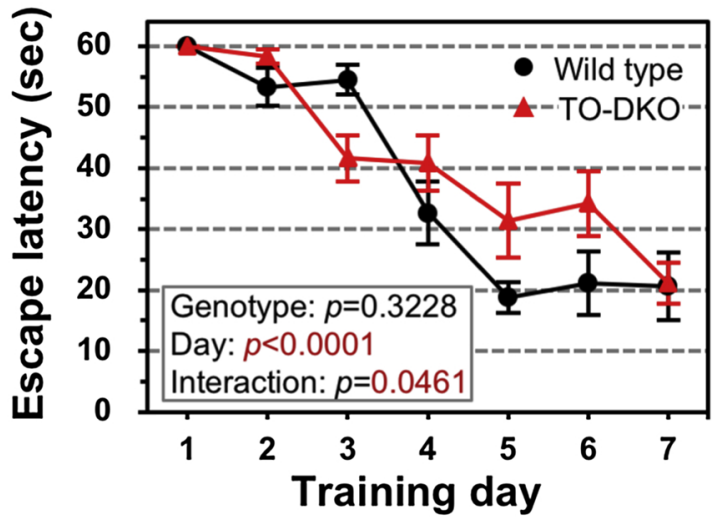

B

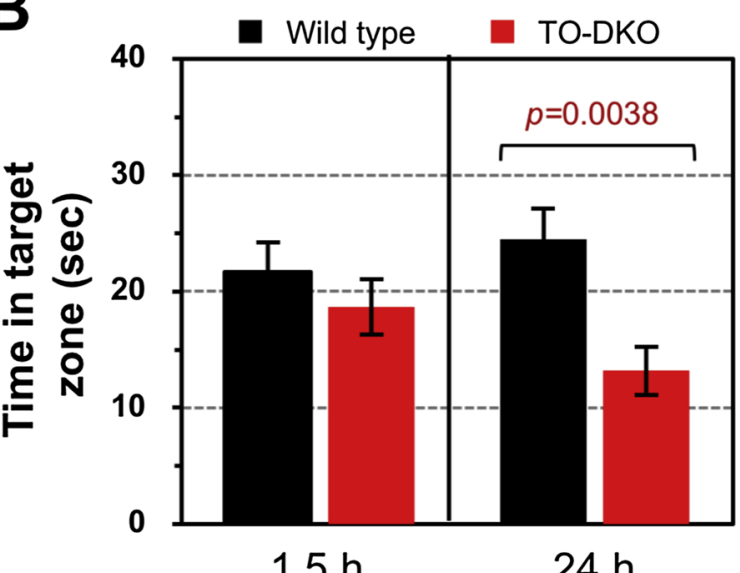

C

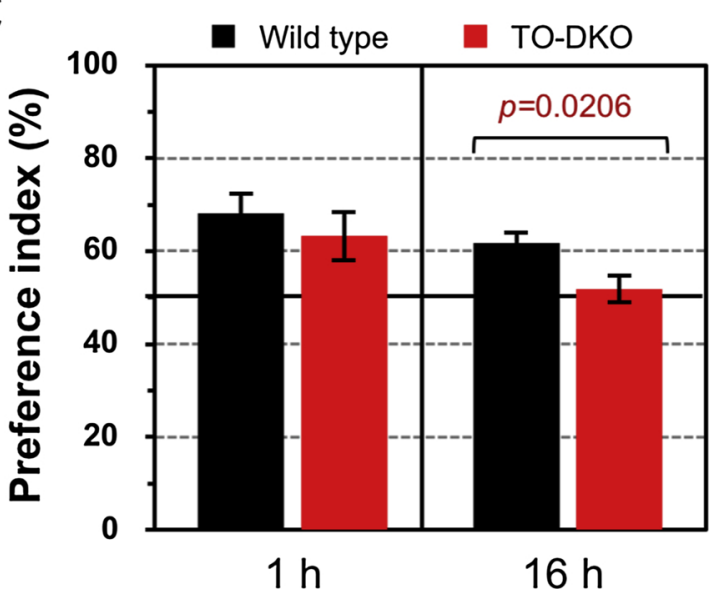

Fig. 3. Age-dependent alteration of cognitive function by MTH1/OGG1-double deficiency.

(A) Hidden-platform acquisition training in Morris water maze. Escape latencies of middle-aged female mice to the hidden platform (sec, mean \pm SEM) are plotted. Black circles, wild-type; red triangles, TO-DKO mice. Numbers of mice in each group: wild-type $(n=8)$; TO-DKO $(n=9)$. Statistical analysis was performed with repeated-measures ANOVA. (B) Probe tests in Morris water maze 1.5 and $24 \mathrm{~h}$ after the last acquisition training. Time spent in the target quadrant for middle-aged female mice (time in target zone, sec, mean \pm SEM) are shown in bar graphs. Black bars, wild-type; red bars, TO-DKO mice. Statistical analysis was performed with Student's t-test. (C) Novel object recognition tests 1 and $16 \mathrm{~h}$ after the sample object exposure. Preference indices for middle-aged female mice (\%, mean \pm SEM) are shown in bar graphs. Black bars, wild-type; red bars, TO-DKO mice. Numbers of mice in each group: wildtype $(n=7)$, TO-DKO $(n=11)$ in left $(1 \mathrm{~h})$; wild-type $(n=8)$, TO-DKO $(\mathrm{n}=11)$ in right $(16 \mathrm{~h})$. Statistical analysis was performed with Student's $t$-test. appear to accumulate high levels of 8-oxoG in their nuclear genome in the absence of MTH1 and OGG1.

\subsection{The number of newly-generated neurons in NAccSh and ICjM was smaller in TO-DKO owing to nuclear 8-oxoG-induced cell death}

To examine whether MTH1/OGG1-double deficiency increasing nuclear 8-oxoG accumulation in neural progenitors or immature neurons in ventral SVZ and NAcc impairs adult neurogenesis in SVZ, we labeled newborn neurons in 55-week-old wild-type and TO-DKO female mouse brains with BrdU. Twenty-four hours after the last injection of BrdU, the density of BrdU-labeled cells in the ventral SVZ was significantly decreased in the TO-DKO brain compared with wild type mice (bregma from +0.745 to $+1.245 \mathrm{~mm}$, Fig. $6 \mathrm{~A}$ and $\mathrm{B}$ ). In the ventral SVZ, a substantial number of BrdU-labeled cells were detected, particularly in the section containing the ICjM (Supplementary Figure S12B, sections \#2 to \#8). In addition, BrdU-positive neurons were also detected in a region between the ventral SVZ and ICjM (Fig. 6A). Twenty-eight days after the last injection of BrdU, the number of BrdUlabeled neurons detected in NAccSh and ICjM of TO-DKO brain was much smaller than that of wild type (Fig. 6C and D).

Because BrdU-labeled neurons were apparently detected in the tangential direction from ventral SVZ to ICjM in the wild-type mouse brain (Supplementary Figure S12C), newborn neurons originating in the ventral SVZ appeared to be lost, probably through increased cell death in the middle-aged female TO-DKO mouse brain. To detect dying cells, we carried out TUNEL staining of middle-aged, female wild-type and TO-DKO mouse brains. As shown in Fig. 7, the density of TUNELpositive cells in the ventral SVZ of TO-DKO brain was almost twice that in the wild-type brain, demonstrating increased apoptosis in the ventral SVZ of middle-aged female TO-DKO brain.

These results demonstrated that MTH1/OGG1-double deficiency significantly increased nuclear 8-oxoG accumulation in proliferating neural progenitors, especially in the ventral SVZ, resulting in apoptotic elimination of newborn neurons.

\subsection{MTH1/OGG1-double deficiency caused atrophy of ICjM in middle- aged female mouse brain, impairing locomotor function}

The current results strongly suggest that newborn neurons originating in ventral SVZ migrate and contribute to the formation of the ICjM in the middle-aged mouse brain. If this is the case, apoptotic elimination of newborn neurons in the middle-aged female TO-DKO brain might result in impaired ICjM formation. Thus, we examined the number of mature neurons in the ICjM using sequential sections prepared from middle-aged female wild-type and TO-DKO mouse brains (Fig. 8A). We found that sequential areas of ICjM in TO-DKO brain sections were smaller than those in wild type mice (Fig. 8B). Moreover, we stereologically estimated that the total number of small granule neurons (5-7 $\mu \mathrm{m}$ in diameter) was significantly smaller in the ICjM of TO-DKO compared with wild type mice (Fig. 8C, left). The estimated volume of the ICjM in TO-DKO mice was also significantly smaller than that of wild type mice (Fig. 8C, right), confirming substantial atrophy of the ICjM in middle-aged female TO-DKO brains.

We then examined the effects of transgenic expression of hMTH1 on the formation of the ICjM (Fig. 8D). Both the total number of ICjM neurons and their estimated volume were significantly greater in old hMTH1-Tg brains compared with wild type mice, consistent with the effects of MTH1 on spontaneous locomotor function and nuclear 8-oxoG accumulation in the NAcc.

In addition, there was a significant positive correlation between the intensity of nuclear 8-oxoG in the NAccSh, including the ICjM, and to a lesser extent in the whole NAcc, with the locomotor counts in $24 \mathrm{~h}$ obtained from three groups of mice (hMTH1-Tg, wild type, TO-DKO). However, the intensity of nuclear 8-oxoG in NAccCo was not correlated with the locomotor counts (Fig. 9A). Moreover, we found that the total 
number of mature neurons in the ICjM and, to a lesser extent, the estimated volume of the ICjM obtained from two groups of mice (wild type, TO-DKO) exhibited significant negative correlations with the locomotor counts in $24 \mathrm{~h}$ (Fig. 9B). These results are consistent with the pivotal roles of the ICjM in the motivational and limbic systems, related to spontaneous locomotor activity.
3.8. In aged female TO-DKO mice, depletion of newborn dopamine receptor D3-positive neurons in NAccSh and ICjM enhanced expression of FOSB/ $\triangle F O S B$ in the NAccCo through disinhibition of dopaminergic neurons projected from the ventral tegmental area

It has been reported that neurons in the ICjM, and to a lesser extent in the NAccSh, express DRD3 (Diaz et al., 1995; Le Moine and Bloch,
A
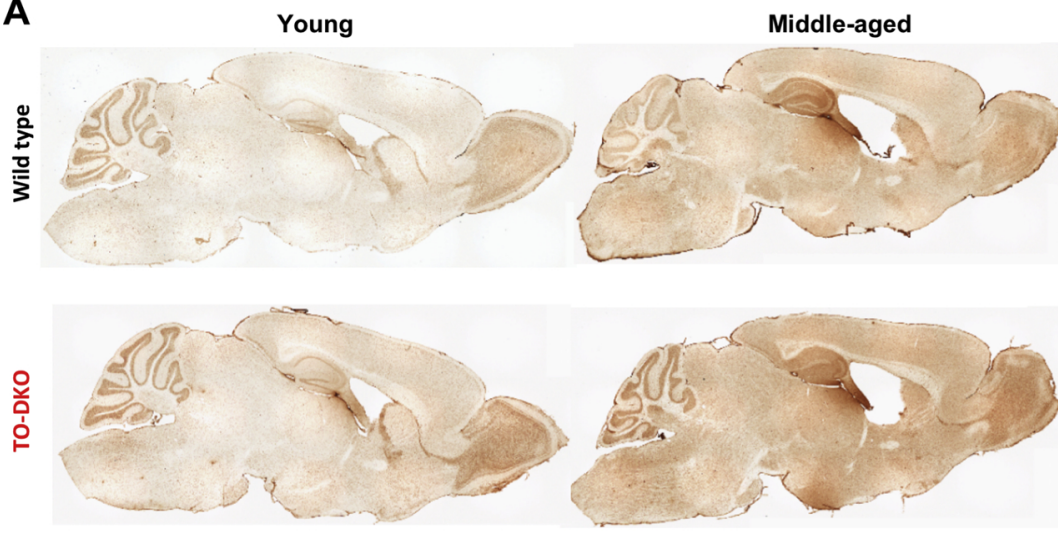
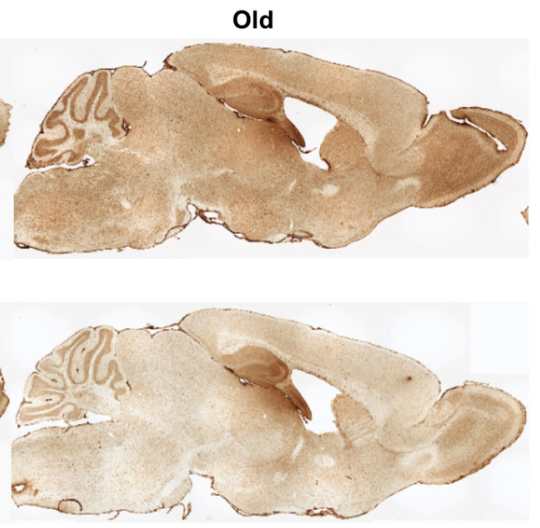

B
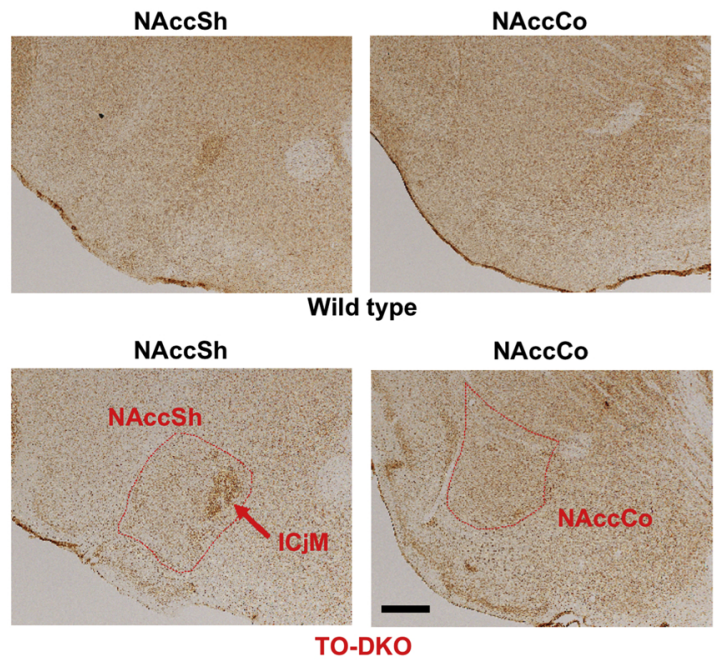

C
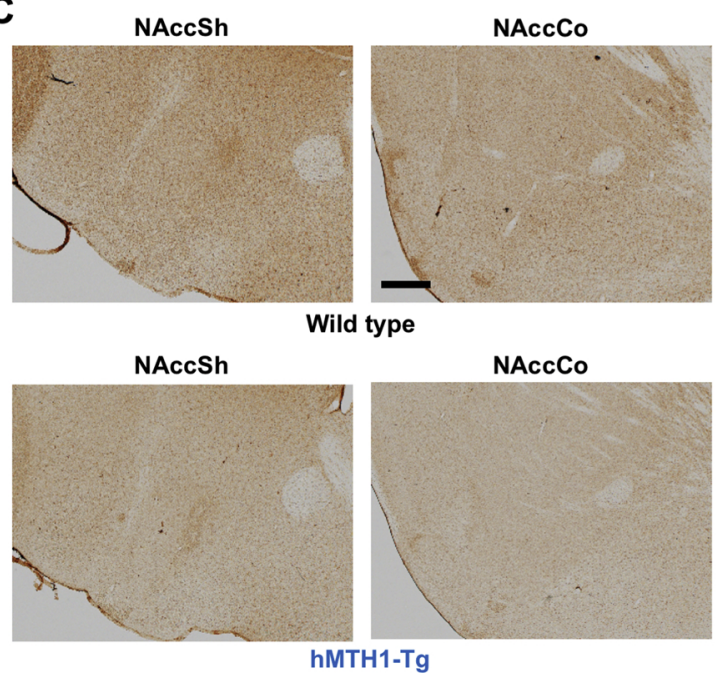

D
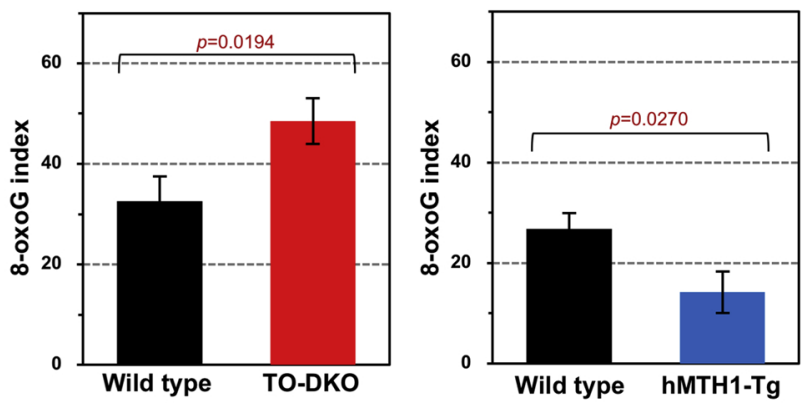

E

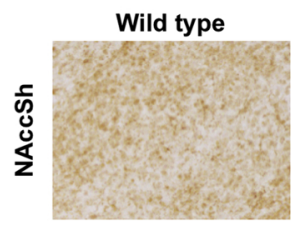

TO-DKO

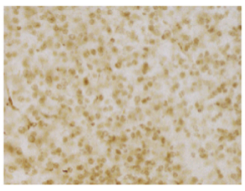

hMTH1-Tg
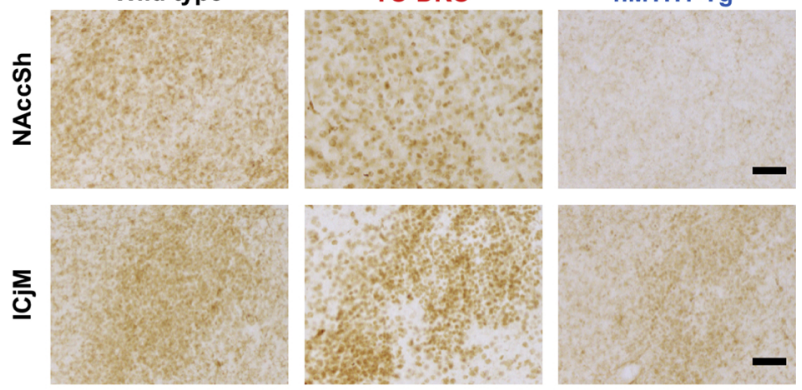

$\mathbf{F}$
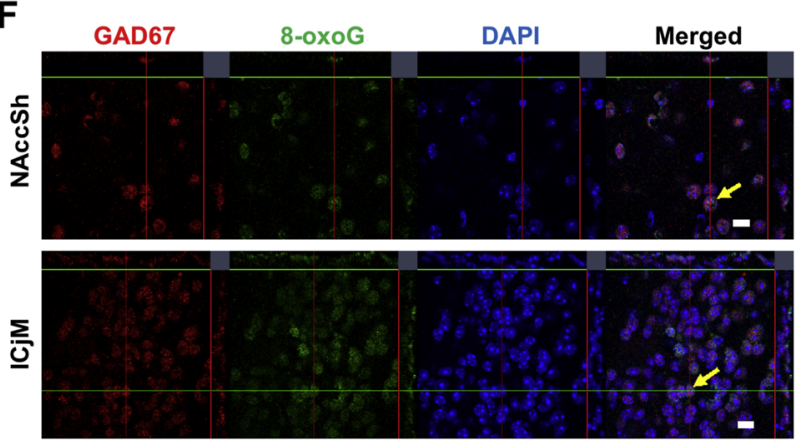

(caption on next page) 
Fig. 4. MTH1/OGG1-deficiency increased 8-oxoguanine accumulation in nuclear genomes of brain, especially neurogenic regions, during aging.

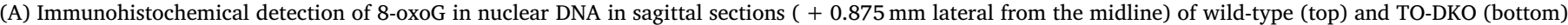

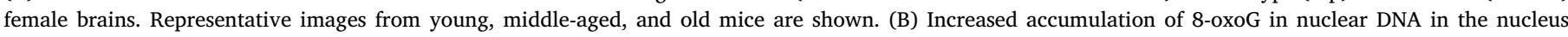

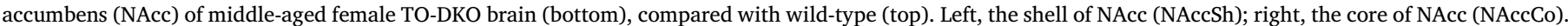

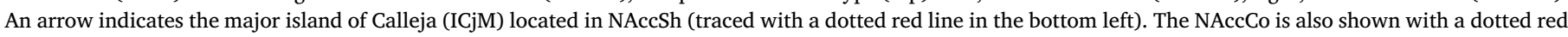

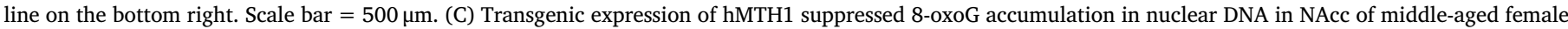

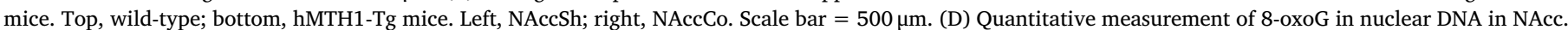

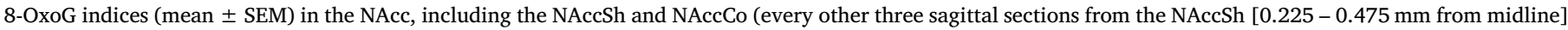

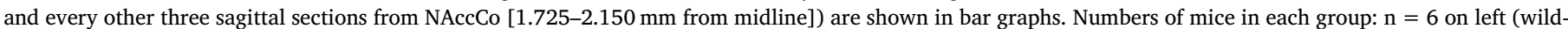

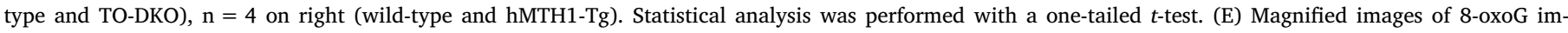

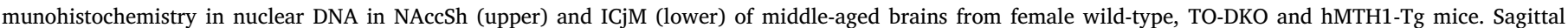

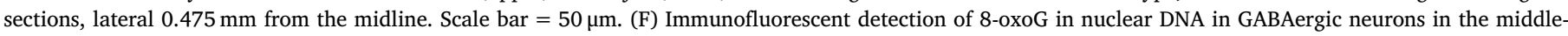

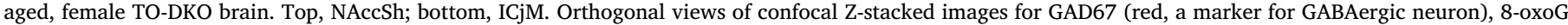
(green), and DAPI (blue)-positive cells (arrow) in a coronal section are shown. Scale bar $=10 \mu \mathrm{m}$.
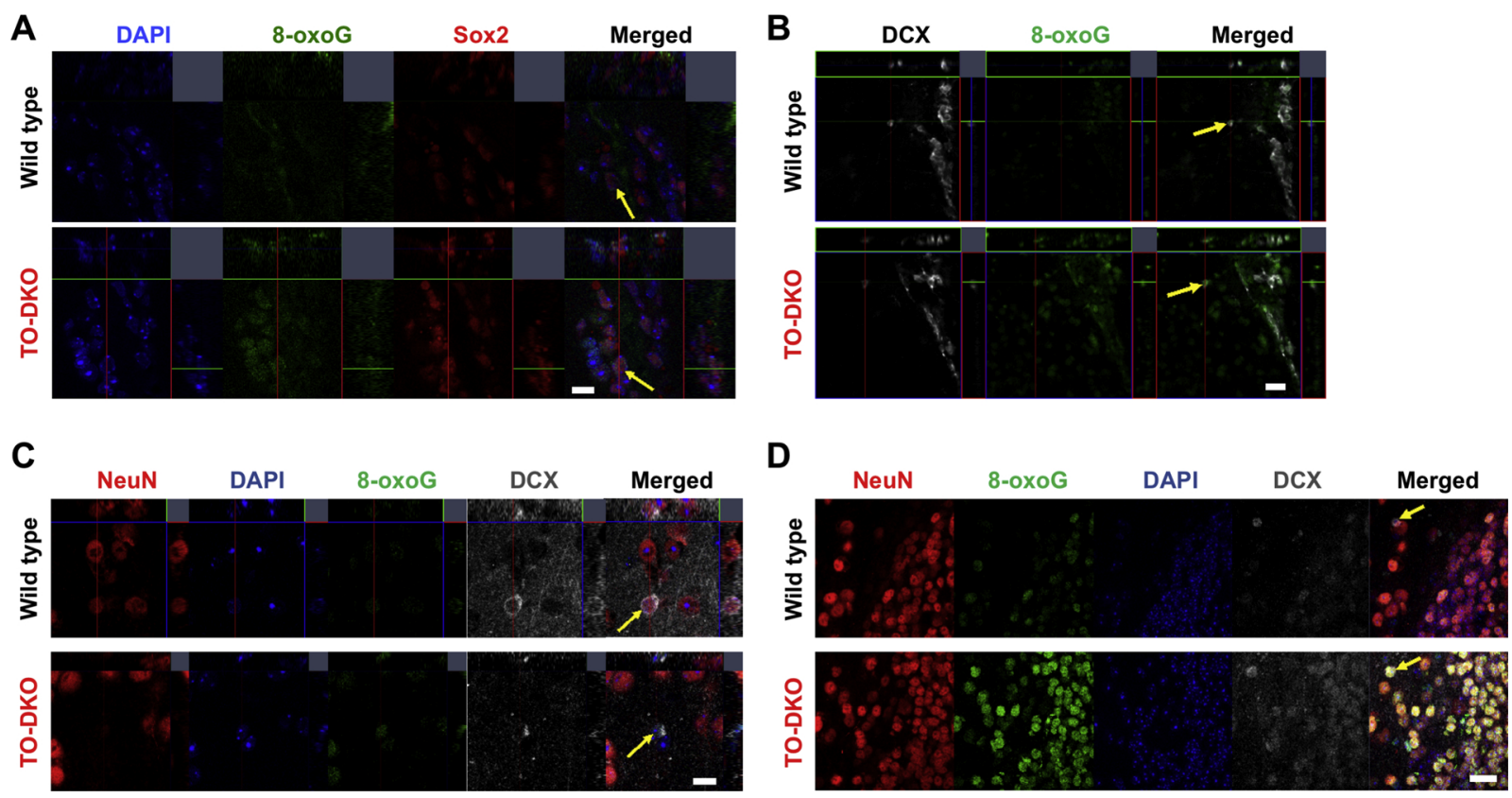

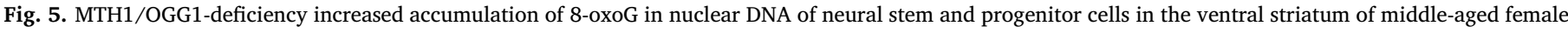
mice.

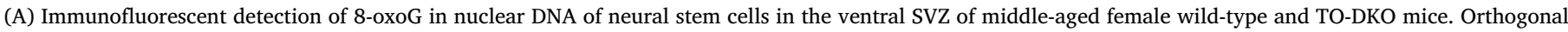

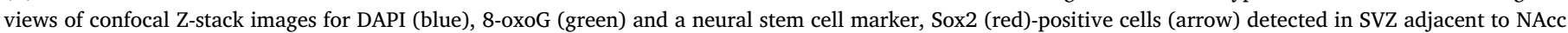

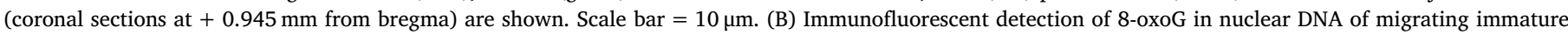

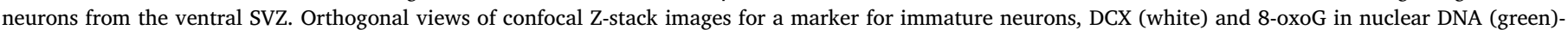

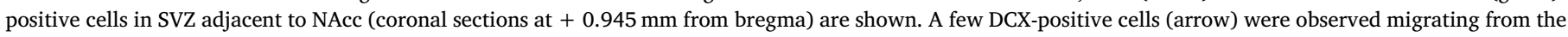

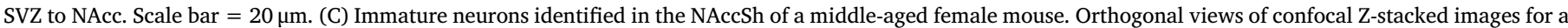

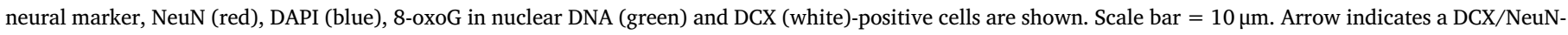

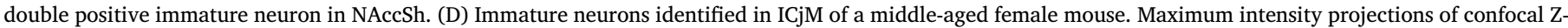

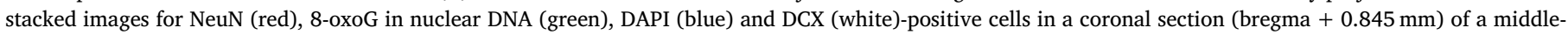

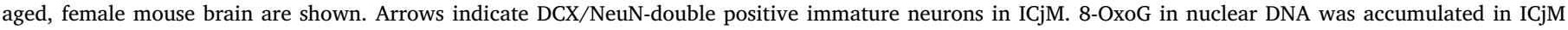
neurons of TO-DKO mice. Scale bar $=20 \mu \mathrm{m}$.

1996), constituting GABAergic inhibitory neurons which negatively regulate dopaminergic neurons in the VTA (Kohnomi and Konishi, 2015; Sokoloff and Le Foll, 2017). In the aged female TO-DKO brain, it is likely that DRD3-positive neurons in ICjM were depleted and dopaminergic neurons in VTA were disinhibited, inducing hyperlocomotor activity through activation of DRD1-positive GABAergic medium spiny neurons (MSNs) in the NAccCo (Wenzel et al., 2015).

As shown in Supplementary Figure S13, we detected DRD3 expression in BrdU-positive newborn neurons in the wild-type ICjM, confirming that the ICjM contains DRD3-positive newborn neurons which are depleted in the middle-aged TO-DKO mouse brain. To examine whether DRD1-positive neurons contribute to the hyperlocomotor activity observed in middle-aged female TO-DKO mice, we administered a DRD1 antagonist, SCH23390 (1.0 mg/kg, i.p.) to middleaged wild-type and TO-DKO female mice and measured locomotor activity in the home cage compared with saline-injected mice (Supplementary Figure S14A). SCH23390 significantly decreased locomotor activity only in TO-DKO mice (Supplementary Figure S14B and C) indicating that hyperlocomotor activity in these mice was dependent on DRD1.

In the NAcc, particularly the NAccCo, DRD1-positive MSNs express FOSB/ $\triangle F O S B$ upon stimulation from dopaminergic neurons in VTA, enhancing locomotor activity (Nestler, 2013; Olsen, 2011; Werme et al., 2002). Immunohistochemistry of FOSB/ $\mathrm{FOSB}$ using anti-FOSB (5G4), which detects both FOSB and $\triangle$ FOSB proteins, revealed that the number of FOSB/ $\triangle$ FOSB-positive cells in the NAccCo was greater in the brains of middle-aged female TO-DKO mice, compared with wild-type mice (Supplementary Figure S15A). In the brains of middle-aged female TODKO mice, the density of FOSB/ $\triangle$ FOSB-positive cells in the NAccCo exhibited a significant positive correlation with the level of nuclear 

A Neun
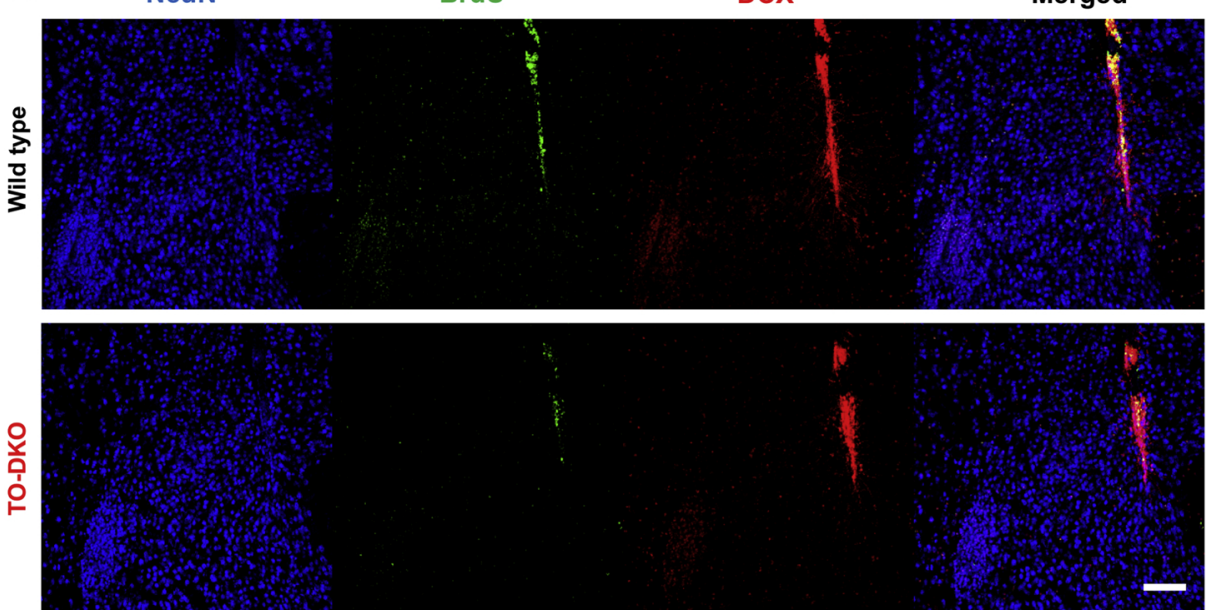

C
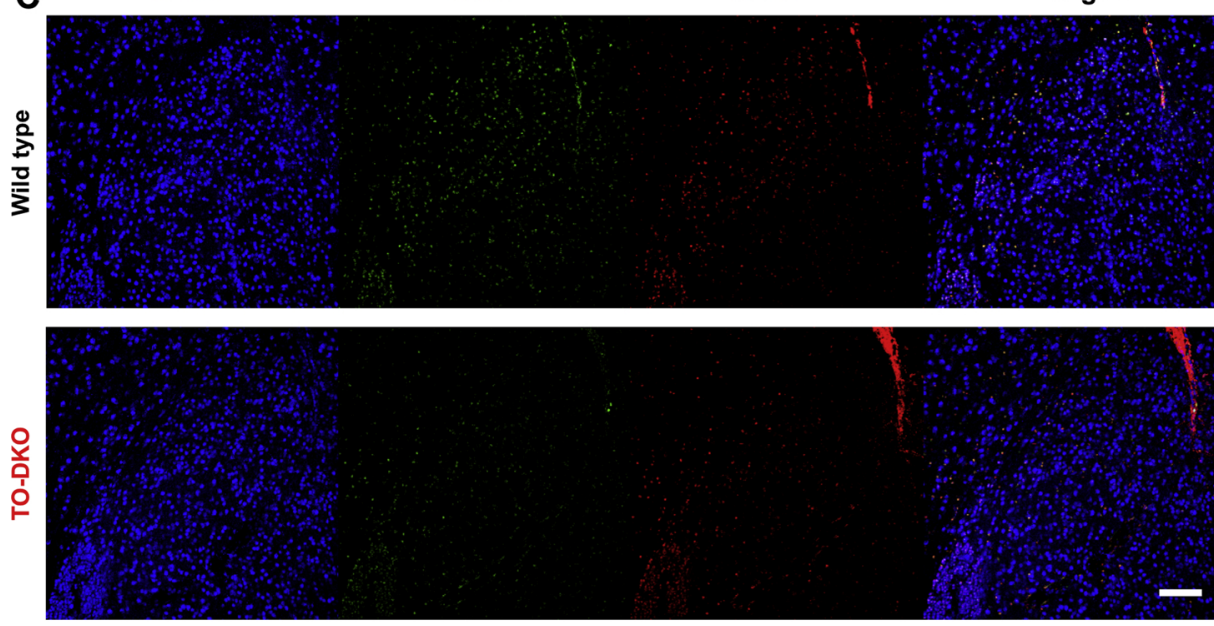

(1)

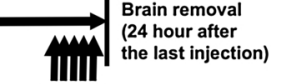

BrdU injection

$50 \mathrm{mg} / \mathrm{kg} \times 1$ daily

for five days

B 500
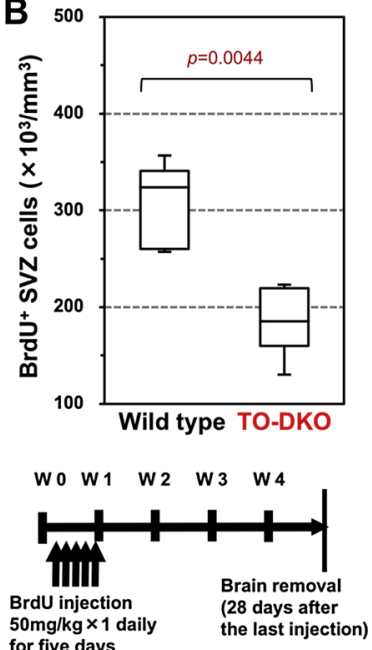

Fig. 6. MTH1/OGG1-deficiency impaired neurogenesis in the ventral striatum of middle-aged female mice.

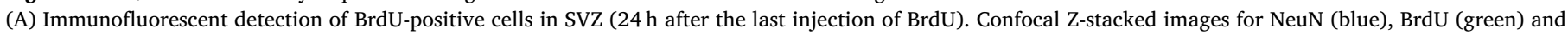

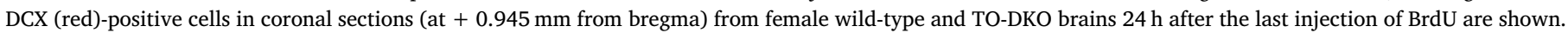

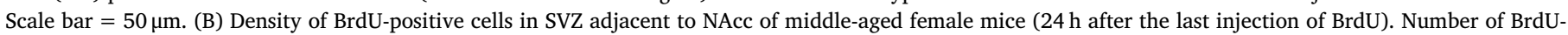

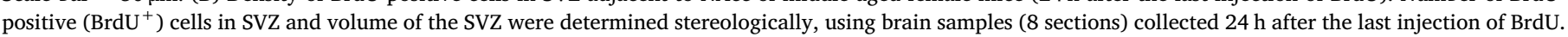

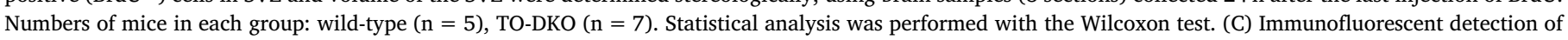

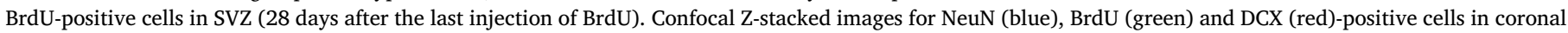

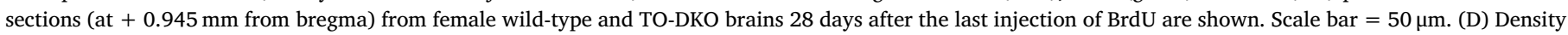

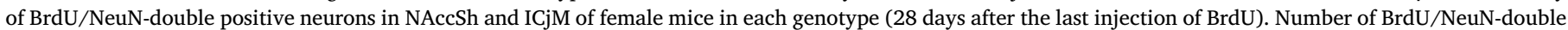

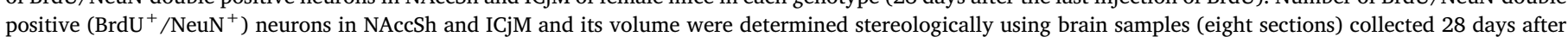
the last injection of BrdU. Number of mice in each group: $n=4$. Statistical analysis was performed with the Wilcoxon test.

8-oxoG in NAccSh, but not in NAccCo itself (Supplementary Figure S15B).

In contrast, the number of FOSB/ $\triangle \mathrm{FOSB}$-positive cells in the NAccCo was not changed in the brains of middle-aged female hMTH1-Tg mice compared with the corresponding wild-type mice. We found no correlation between the density of these cells and the levels of nuclear 8-oxoG in the NAccSh or the NAccCo (Supplementary Figure S15C and D).

Locomotor activity among middle-aged female wild-type and TODKO mice exhibited a significant positive correlation with the densities of FOSB/ $\triangle$ FOSB-positive cells in the NAccCo (Supplementary Figure $\mathrm{S} 15 \mathrm{E})$. Taken together, our results revealed that increased nuclear 8oxoG accumulation in neural progenitors in SVZ during aging in female TO-DKO mice causes depletion of newborn DRD3-positive neurons in the NAccSh and ICjM, enhancing expression of FOSB/ $\triangle \mathrm{FOSB}$ in the NAccCo through disinhibition of dopaminergic neurons projected from VTA.

It has been shown that calretinin-positive interneurons are also continuously supplied into the adult striatum from SVZ (Dayer et al., 2005), suggesting that MTH1/OGG1-double deficiency may also cause their depletion in ICjM or islands of Calleja (ICj), thus contributing to impaired locomotor function. However, as shown in Supplementary Figure S16, calretinin/BrdU-double positive interneurons were barely detected in both ICjM and ICj of middle aged wild-type female mice (Supplementary Figures S16, S17). These results also suggest that the impaired locomotor function observed in TO-DKO mice was mainly caused by depletion of DRD3-positive interneurons.

3.9. Increased nuclear 8-oxoG accumulation in the dentate gyrus of middleaged female TO-DKO mouse hippocampus impaired neurogenesis, leading to dentate gyrus atrophy

In addition to the ventral SVZ and striatum, we found that the intensity of nuclear but not mitochondrial 8-oxoG in the DG of the middle-aged female TO-DKO hippocampus was significantly greater 
A

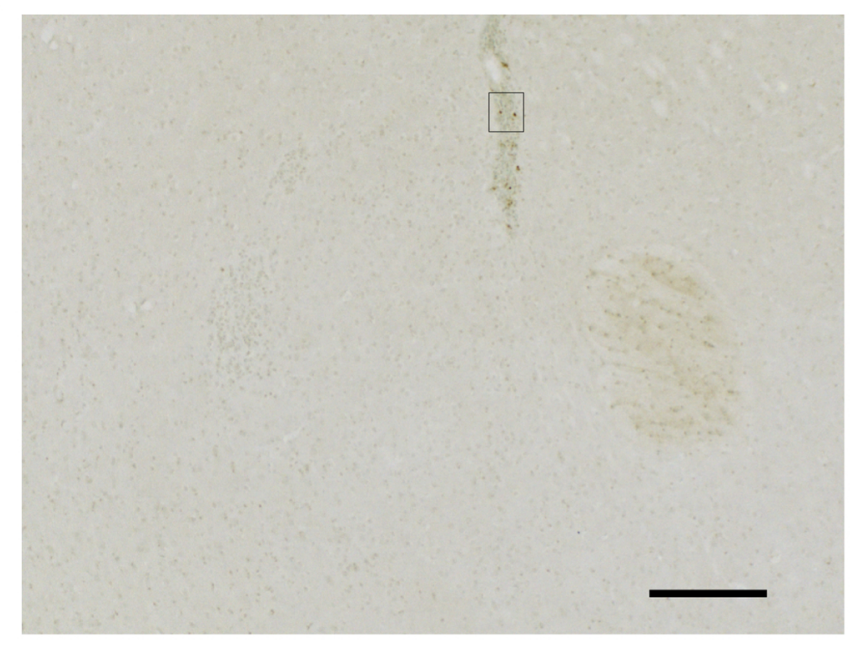

B

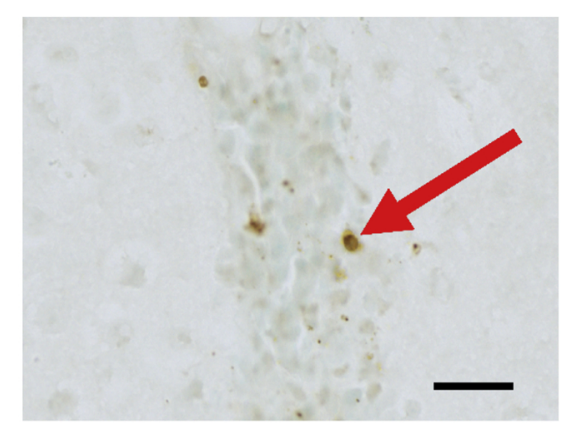

C

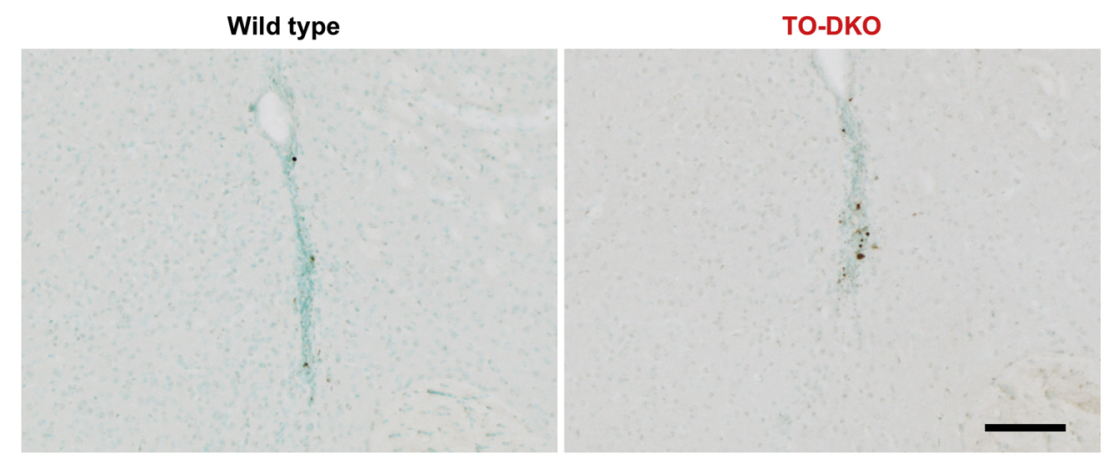

D

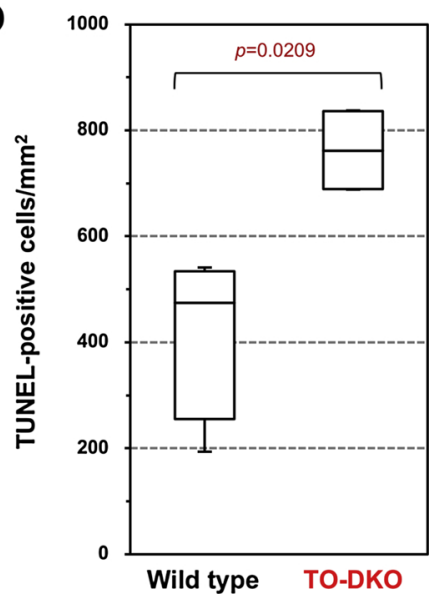

Fig. 7. Detection of apoptotic cells in SVZ of middle-aged female mice.

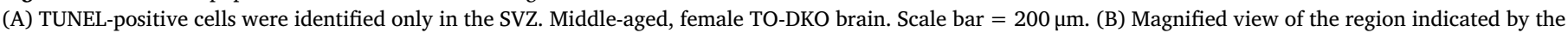

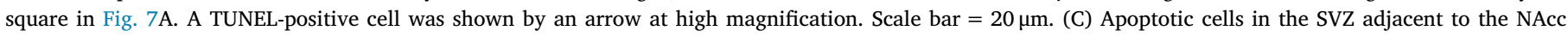

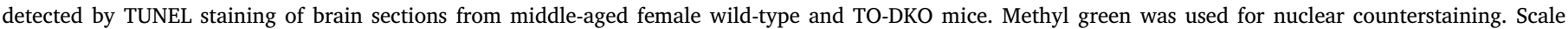

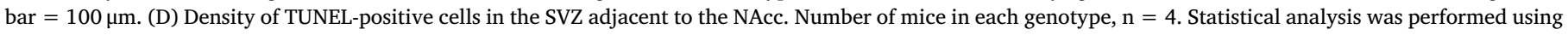
the Wilcoxon test.

than that in the corresponding wild-type hippocampus (Fig. 10A, Supplementary Figure S18A). As anticipated, the intensity of nuclear 8oxoG in the DG of middle-aged hMTH1-Tg hippocampus was significantly lower than that of the corresponding wild-type hippocampus (Fig. 10B). When FOSB/ $\triangle$ FOSB expression was measured in the DG, we found that the density of FOSB/ $\triangle$ FOSB-positive cells was significantly increased in the TO-DKO hippocampus (Supplementary Figure S18B) while no changes were observed in the middle-aged female hMTH1-Tg hippocampus compared with the corresponding wild type mice. We then measured the area of the DG using differential interference contrast microscope (DIC) images, and found that the mean area in middleaged female TO-DKO, but not hMTH1-Tg mice, was significantly smaller than that in the corresponding wild-type hippocampus (Supplementary Figure S18B and C).

We also found that intensities of nuclear 8-oxoG among middle-aged female wild-type and TO-DKO DG mice exhibited significant positive correlations with densities of FOSB/ $\mathrm{FOSB}$-positive cells in DG (Supplementary Figure S18D, left). In contrast, the 8-oxoG intensities exhibited significant negative correlations with areas of DG (Supplementary Figure S18D, right).

Twenty-four hours after the last injection of BrdU, we found that total number of $\mathrm{BrdU}^{+}, \mathrm{BrdU}^{+} / \mathrm{DCX}^{+}$, and $\mathrm{BrdU}^{+} / \mathrm{DCX}^{+} / \mathrm{NeuN}^{+}$cells in the DG of middle-aged female TO-DKO hippocampus were significantly lower compared with the corresponding wild type mice (Fig. 10C and D). Moreover, the estimated DG volume in middle-aged TO-DKO mice was significantly smaller than that of wild type mice (Fig. 10E), indicating DG atrophy.

\section{Discussion}

Overall, the current findings revealed that MTH1/OGG1-double deficiency, in combination with increased oxidative stress occurring during aging, impairs neurogenesis in both SVZ and DG through incorporation of 8-oxo-dGTP into the nuclear genome of proliferating neural progenitors. This reduces the functional supply of newborn neurons to the ICjM and DG, leading to atrophy of both the ICjM and DG, particularly in female mice. The former is most likely to be involved in suppressing the age-dependent decline of spontaneous locomotor activity, and the latter is likely to cause mild impairment of longterm memory retrieval, as observed in aged female TO-DKO mice, as sexually dimorphic phenotypes.

Older animals have been reported to exhibit higher nuclear levels of oxidatively damaged DNA, measured as 8-oxoG, 8-oxo-dG and formamidopyrimidine DNA glycosylase sensitive sites in several organs, 
A

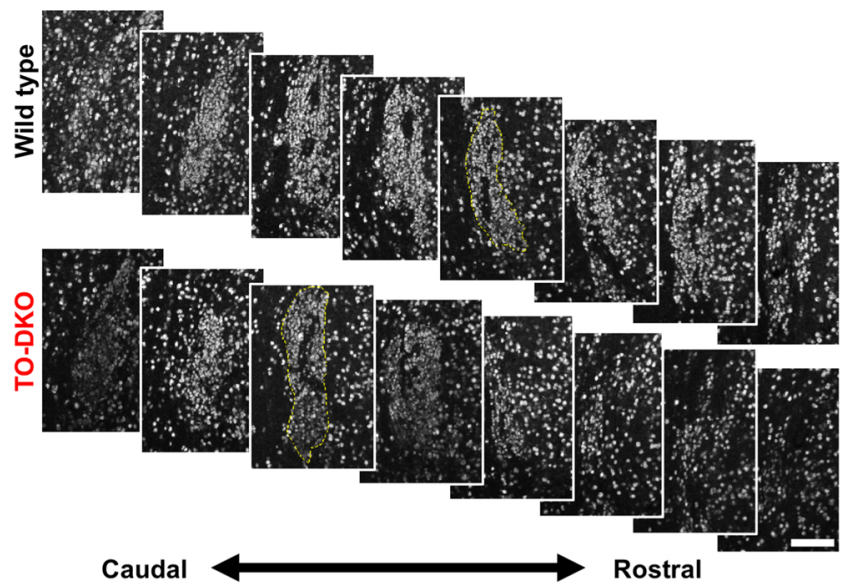

B

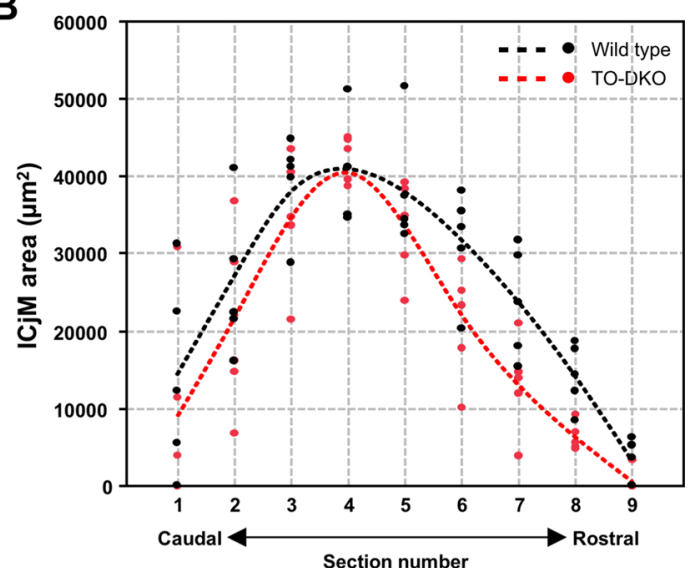

C

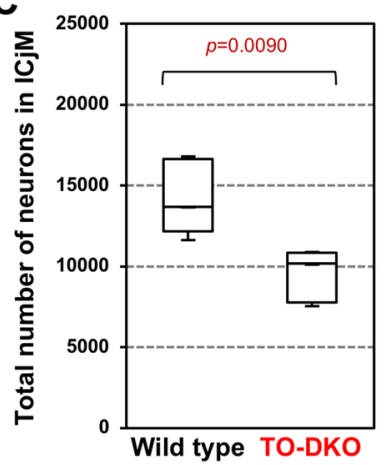

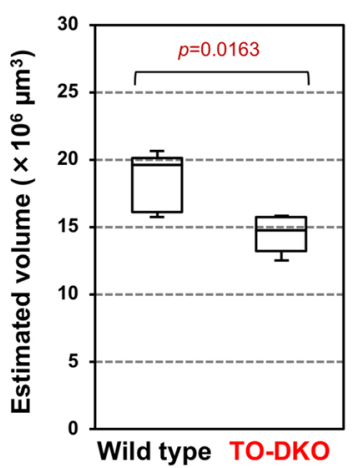

D

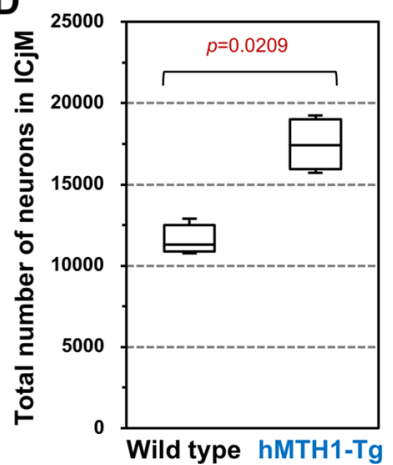

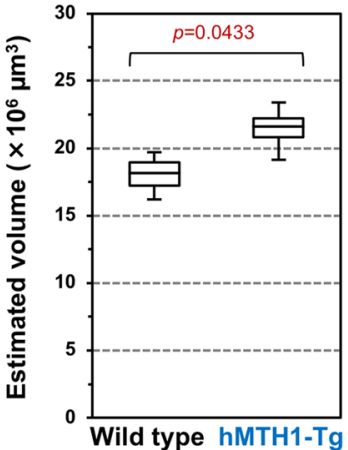

Fig. 8. MTH1/OGG1-double deficiency caused atrophy of ICjM and transgenic expression of hMTH1 results in its hypertrophy.

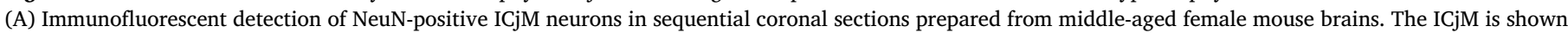

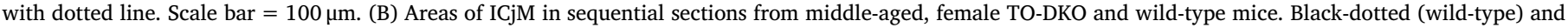

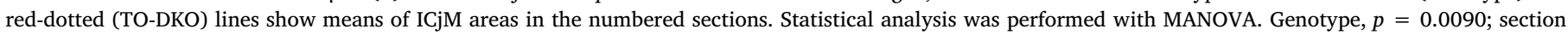

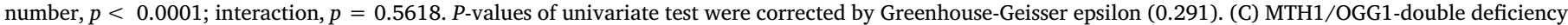

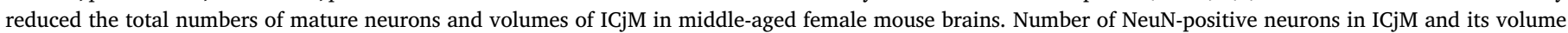

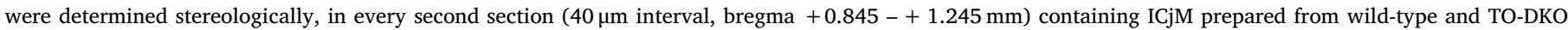

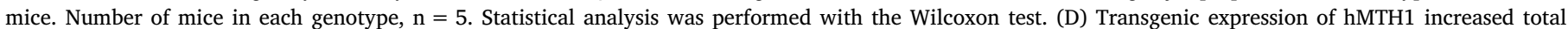

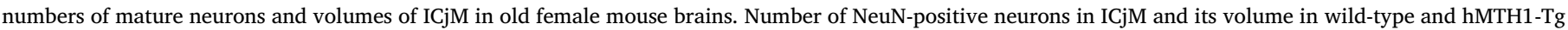
mice were determined as described above. Number of mice in each genotype, $n=4$. Statistical analysis was performed with the Wilcoxon test.

particularly in the brain, kidney, liver, and lung. The accumulation of oxidatively damaged DNA is likely to be present in most, if not all, organs containing mainly terminally differentiated cells, since organs with highly proliferating cells, such as the intestine, spleen, and testis, were reported to show more equivocal or an absence of effects of age on the nuclear levels of damage (Moller et al., 2010). It is likely that levels of 8-oxoG accumulation in nuclear DNA increase throughout the brain during aging in wild-type mice, with the levels in the DG, olfactory bulb, cerebellum and NAcc showing a tendency to be higher compared with surrounding areas throughout life. Compared with the wild-type brain, the brains of TO-DKO mice with MTH1/OGG1-double deficiency, particularly females, exhibited significantly increased levels of 8-oxoG in nuclear DNA of neurons in the ICjM, NAccSh, and DG during aging, while transgenic expression of hMTH1 significantly reduced the levels of 8-oxoG in nuclear DNA of newborn neurons in these regions during aging (Figs. 4B-F and 5A). These results indicate that neurons in specific regions of the aging female brain have incorporated 8-oxo-dGTP into their nuclear genomes during their replication, suggesting that those neurons were newly supplied by adult neurogenesis during aging.

By tracing newborn neurons incorporating BrdU, we demonstrated for the first time that newborn neurons are consistently supplied to the NAcc, particularly the ICjM, which contains mostly DRD3-positive neurons, from SVZ, in addition to the granule neurons in DG supplied from SGZ. Previous studies reported intrastriatal migration of new
GABAergic granule cell-like interneurons from the early postnatal SVZ into the striatum, forming the ventral migratory mass (De Marchis et al., 2004; Inta et al., 2008). The findings of the present study indicate that this process occurs throughout life in the mouse brain, consistent with adult neurogenesis of GABAergic interneurons in the human striatum/caudate nucleus (Ernst et al., 2014). We found that MTH1/ OGG1-double deficiency in female mice significantly reduced the density of BrdU-positive newborn cells in the SVZ and BrdU-positive neurons in the NAcc. Densities of TUNEL-positive cells in the SVZ of female TO-DKO mice were significantly higher than those of wild type mice, suggesting that apoptotic elimination of neural progenitors or newborn neurons significantly increased in the absence of MTH1 and OGG1. Indeed, the brains of female TO-DKO mice exhibited apparent atrophy of both ICjM and DG (Figs. 8A-C, 10C-E).

We previously reported that proliferating cells accumulating increased levels of 8-oxoG in nuclear DNA undergo apoptosis that is dependent on MUTYH, poly(ADP) ribose polymerase (PARP), and apoptosis-inducing factor (AIF). The DNA glycosylase activity of MUTYH, by excising the adenine inserted opposite template 8-oxoG during the next round of replication, increases the formation of single-strand breaks (SSBs), particularly during the futile cycles of BER, because adenine as well as cytosine can be reinserted opposite 8-oxoG during repair replication. Accumulation of SSBs in the nuclear genome might chronically activate PARP and induce PARP-AIF dependent apoptosis 
A

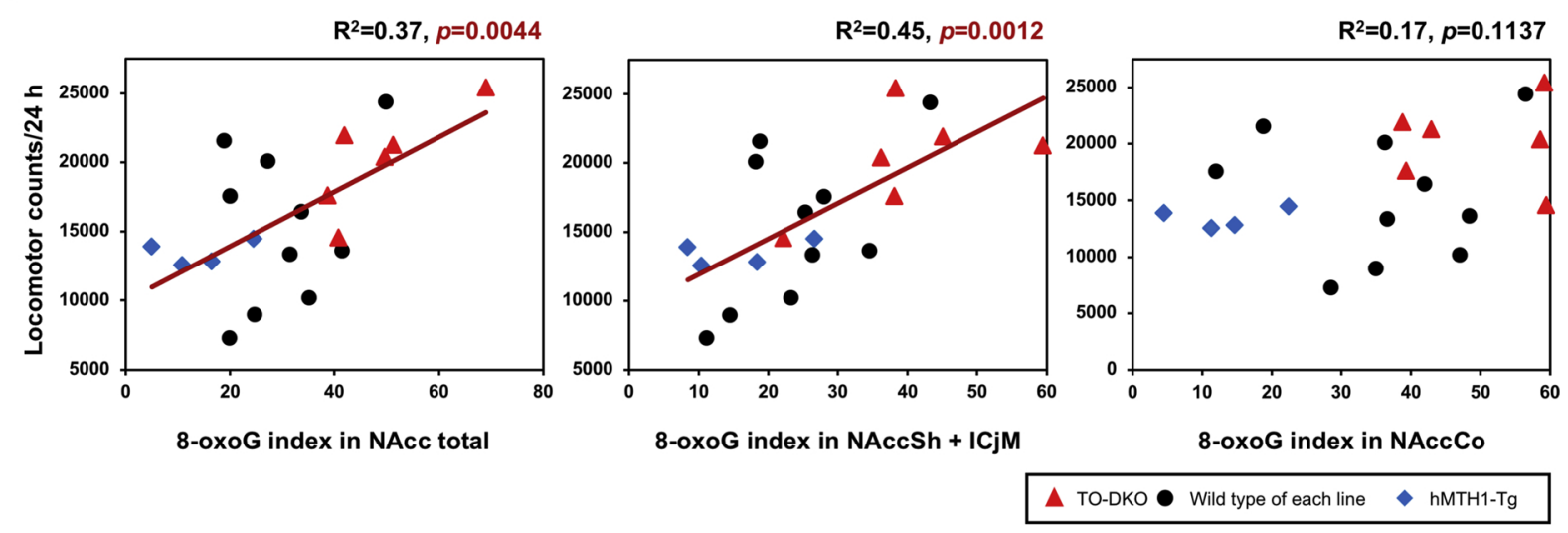

B

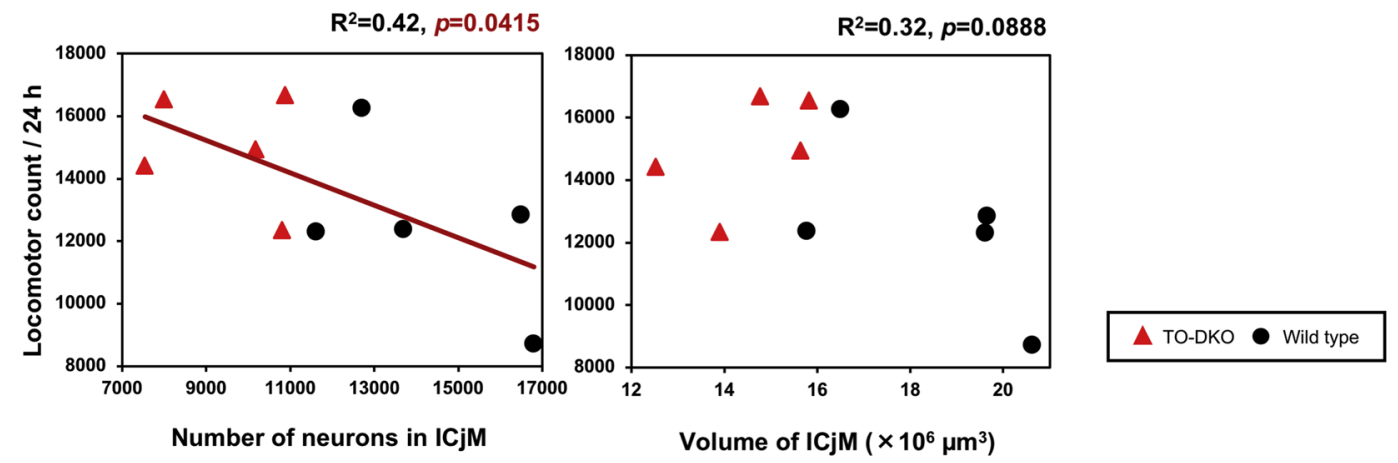

Fig. 9. Correlation between altered spontaneous locomotor activity, 8-oxoG accumulation, and ICjM atrophy.

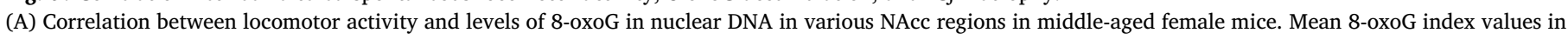

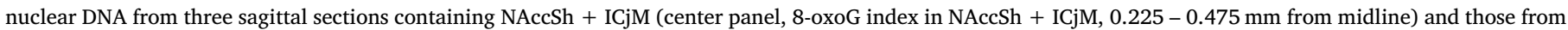

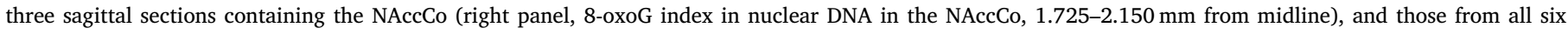

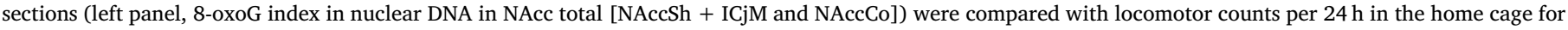

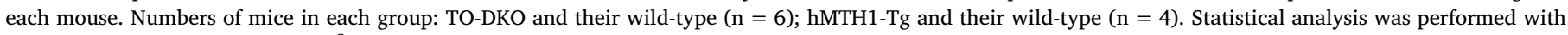

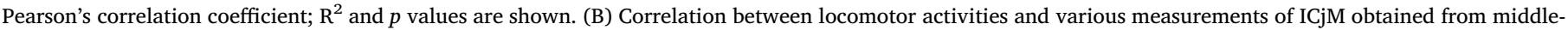

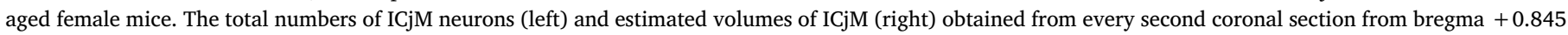

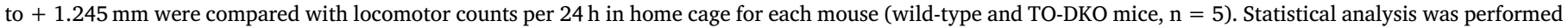
with Pearson's correlation coefficient test; $\mathrm{R}^{2}$ and $p$ values are shown.

(Nakabeppu, 2017; Oka et al., 2008). In the absence of MTH1, the level of 8-oxo-dGTP in the nucleotide pool must be highly increased, and thus proliferating neural progenitors will incorporate increased levels of 8-oxo-dGTP into their genome. In the absence of OGG1, unrepaired 8 -oxoG in the nuclear genome will induce apoptosis, as observed in TODKO brains of female mice with ICjM and DG atrophy.

The ICjM mainly contains DRD3-positive GABAergic neurons projecting into VTA, from where dopamine neurons project into NAccCo with DRD1-positive postsynaptic MSNs constituting accumbens/striatal circuitry (Diaz et al., 1995; Le Moine and Bloch, 1996; Li and Kuzhikandathil, 2012; Koeltzow et al., 1998). Therefore, ICjM atrophy would reduce inhibitory regulation of the dopaminergic VTA neurons, increasing dopamine release in NAccCo, which in turn stimulates DRD1-positive MSNs in NAccCo. We observed an increased number of NAccCo neurons expressing FOSB/ $\mathrm{FOSB}$, a marker for chronic neural activation (Hope et al., 1994; Hu et al., 2002; Laine et al., 2017), in middle-aged female TO-DKO mice. This increase was positively correlated with levels of 8-oxoG in nuclear DNA in NAccSh, but not in $\mathrm{NAccCo}$, indicating that dopaminergic neurons in NAccCo are hyperactive in the TO-DKO brain.

During aging, spontaneous locomotor activity of mice in the home cage significantly decreased, particularly in the dark phase. MTH1/ OGG1-double deficiency, especially in female mice, significantly suppressed this age-dependent decline of locomotor activity. Because locomotor activity is positively correlated with the levels of 8-oxoG in nuclear DNA in NAccSh and ICjM, and negatively correlated with the total number of neurons in the ICjM (Fig. 9), ICjM atrophy is most likely to constitute the causative lesion for the hyperlocomotor phenotype in female TO-DKO mice, as seen in DRD3-KO mice (Xu et al., 1997; Klinker et al., 2017). Administration of a DRD1 antagonist, SH23390, to middle-aged female TO-DKO mice significantly decreased locomotor activity during the dark phase but did not affect wild-type mice. We conclude that DRD1-positive neurons in the NAccCo, whose activity is stimulated by dopamine released from dopaminergic neurons projecting from VTA, are responsible for hyperlocomotor activity under dysfunction of DRD3-positive GABAergic neurons in ICjM, as seen in aged female TO-DKO mice.

Mild impairment of long-term memory retention in TO-DKO female mice, as revealed by the probe test in the MWM and the novel object recognition test, is likely to result from DG atrophy, which was likely to be caused by apoptotic elimination of proliferating neural progenitors because of the accumulation of 8-oxoG in nuclear DNA in this area.

Importantly, the current results revealed that MTH1/OGG1-double deficiency caused a female-specific impairment in adult neurogenesis in both DG and SVZ, resulting in mild memory impairment and a hyperlocomotor phenotype only in females during aging, as novel sexually dimorphic phenotypes. Sex-related differences in the neurobiology of social behavior have been well documented in memory, emotion, and recovery from brain injury across the animal kingdom, and are mostly attributed to sex hormones (Choleris et al., 2018). Regarding 
neurogenesis, sex hormones are known to regulate neurogenesis in both DG and SVZ throughout life, although the main sex hormones, estrogens, androgens and progestogens, act on different steps of neurogenesis. Thus, cell proliferation seems to be increased by estrogens only, while androgens and progestogens favor neural renewal by increasing cell survival; differentiation is a common target (Pawluski
A

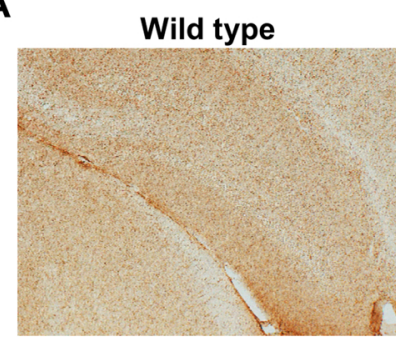

Wild type
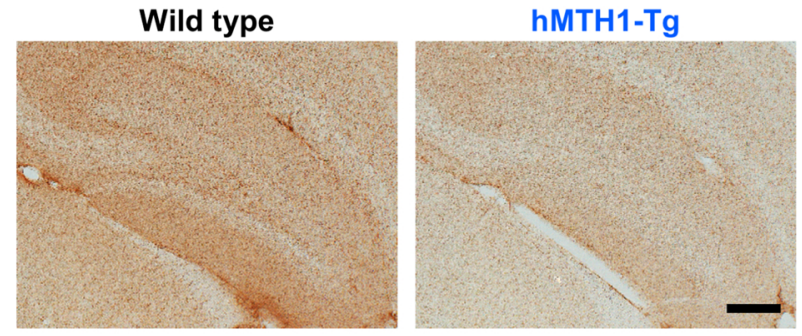

TO-DKO

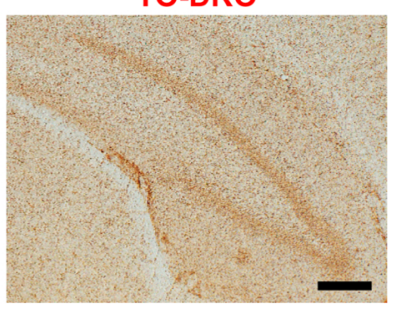

B
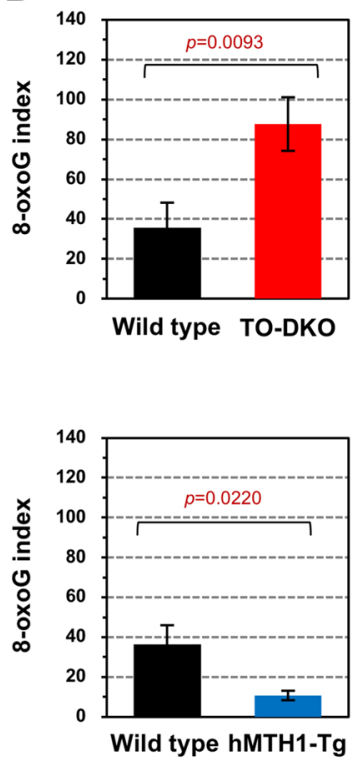

C

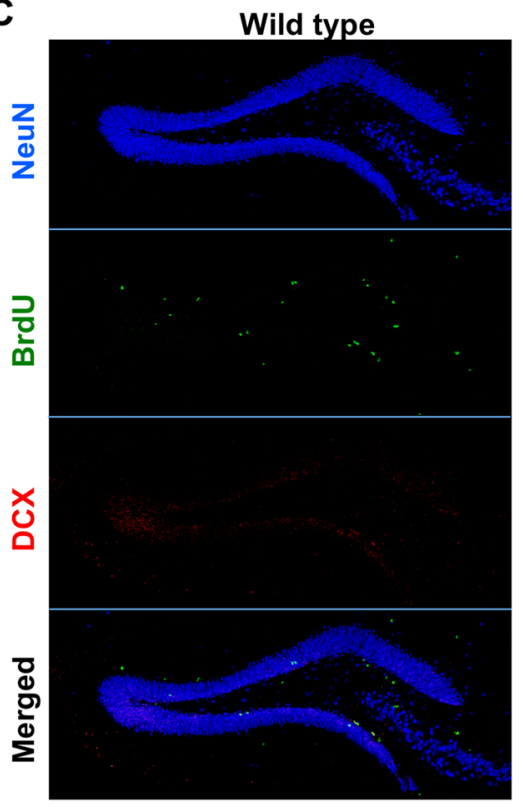

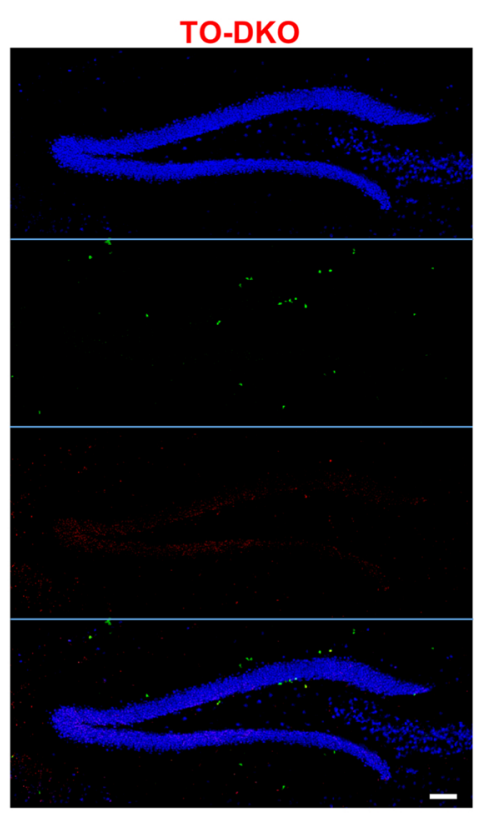

E

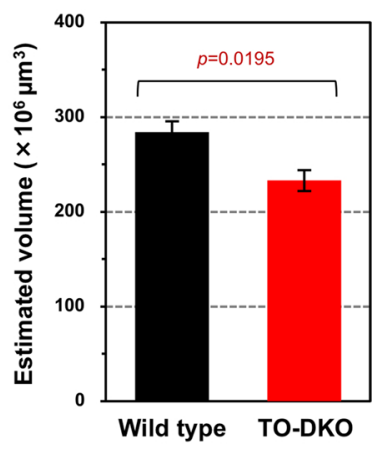

D
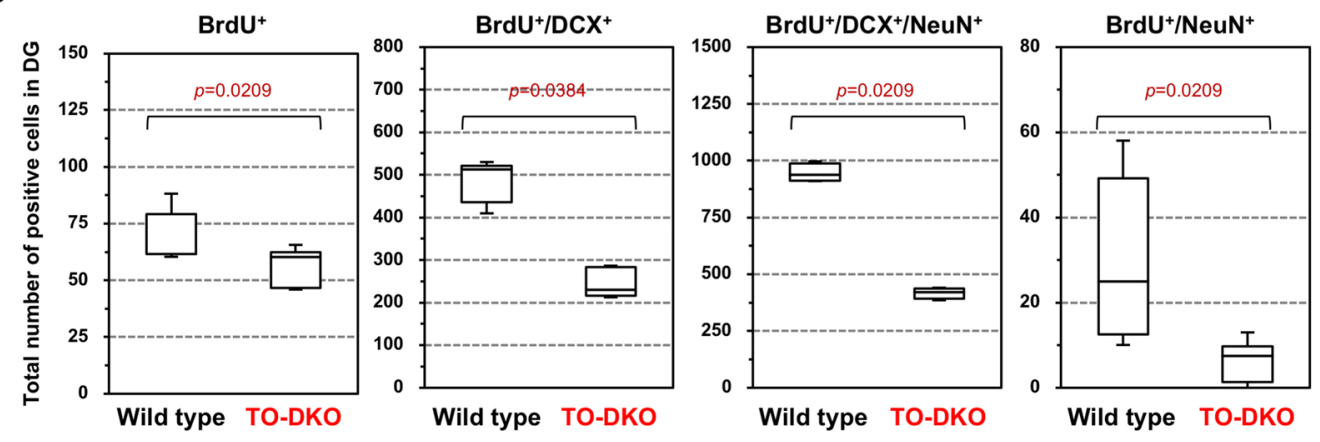

(caption on next page) 


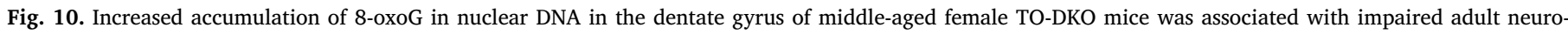
genesis.

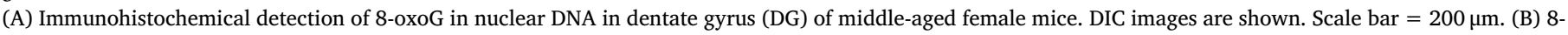

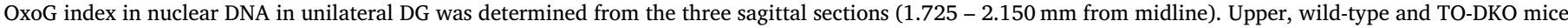

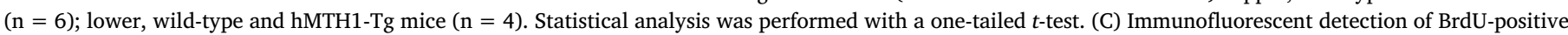

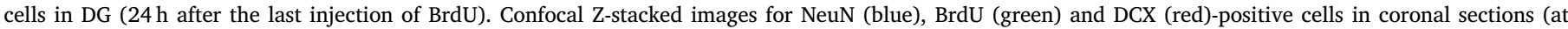

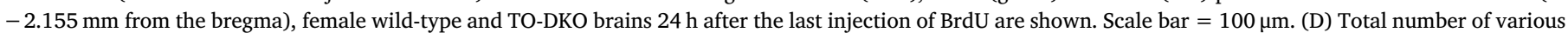

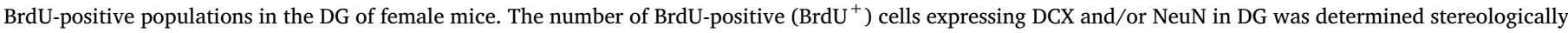

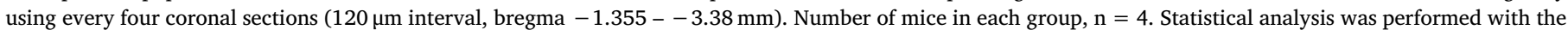

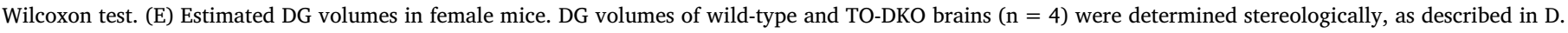
Statistical analysis was performed using Student's $t$-test.

et al., 2009; Duarte-Guterman et al., 2015; Farinetti et al., 2015; Mahmoud et al., 2016; Heberden, 2017; Ponti et al., 2018). Moreover, aging is characterized by a decrease in the rate of neural renewal and in the levels of circulating sex hormones (Heberden, 2017). Thus, sex-related differences in brain function may be more prominent in the aging brain.

The current results revealed that female mice consistently exhibited higher locomotor activity in the home cage than male mice throughout life, and the activity decreased gradually during aging in both sexes. In addition, we found that transgenic expression of hMTH1 decreased locomotor activity, particularly in aged female mice with reduced 8oxoG accumulation in nuclear DNA of newborn neurons in SVZ and DG, indicating that part of the hyperlocomotor phenotype seen in wild-type female mice is caused by incorporation of 8-oxo-dGTP into nuclear DNA in newborn neurons during neurogenesis. This observation suggests that female mice are more prone to generating 8-oxo-dGTP, particularly during neurogenesis, compared with male mice. Previous studies reported that estrogen stimulates proliferation and differentiation of neural stem/progenitor cells (Okada et al., 2010; Gkikas et al., 2017), regulating neurogenesis in a female-specific manner during the estrus cycle (Duarte-Guterman et al., 2015; Ponti et al., 2018; Saravia et al., 2004).

Estrogen activates estrogen receptors (ERs), and regulates the transcription of downstream target genes, either directly via dimerization and binding to estrogen response element (ERE) of DNA, or indirectly through interaction with co-factors such as AP-1 and Sp-1. In addition, some of the effects of estrogen via ERs are rapid, and are known to be mediated through membrane-associated ERs (Gkikas et al., 2017). Estrogen-dependent induction of ERs-regulated targets requires specific histone lysine demethylases, LSD1 which catalyzes FAD-dependent histone demethylation from mono- and dimethylated Lys4 of histone H3 (H3K4me1/2), and possibly H3K9me1/2 (Perillo et al., 2008; Forneris et al., 2009). It has been shown that LSD1 regulates neural stem cell proliferation (Sun et al., 2010) and neurogenesis (Laurent et al., 2015; Fiszbein and Kornblihtt, 2016; Hirano and Namihira, 2016), as does estrogen. Because LSD1 catalyzes demethylation of $\mathrm{H} 3 \mathrm{~K} 4 \mathrm{me} 1 / 2$ or $\mathrm{H} 3 \mathrm{~K} 9 \mathrm{me} 1 / 2$ as a $\mathrm{FAD}$-dependent amine oxidase, hydrogen peroxide $\left(\mathrm{H}_{2} \mathrm{O}_{2}\right)$ is inevitably produced: $\left[\mathrm{H}_{3}\right.$-Lys- $\mathrm{CH}_{3}+$ $\mathrm{O}_{2}+\mathrm{H}_{2} \mathrm{O} \rightarrow \mathrm{H}_{3}$-Lys $+\mathrm{H}_{2} \mathrm{O}_{2}+\mathrm{HCHO}$ (Forneris et al., 2005). This may cause 8-oxoG accumulation in nuclear DNA (Perillo et al., 2008; Seifermann and Epe, 2017). These findings indicate that the estrogenER-LSD1 axis is a unique source for nuclear ROS production in neural stem/progenitor cells.

It has been proposed that $\mathrm{H}_{2} \mathrm{O}_{2}$ production dependent on LSD1 might directly oxidize guanine in DNA to which ERs bind together with LSD1 (Perillo et al., 2008; Seifermann and Epe, 2017). However, the current results indicate that 8-oxoG levels in nuclear DNA in both NAcc and DG of middle-aged hMTH1-Tg female mice were significantly lower than those in wild-type female mice (Figs. 4D and 6A). This indicates that nuclear 8-oxoG in both NAcc and DG in wild-type female mice is derived from 8-oxo-dGTP generated in the nucleotide pool. It is possible that proliferating neural stem/progenitor cells in the female brain, particularly in the proestrus cycle, produce significant levels of $\mathrm{H}_{2} \mathrm{O}_{2}$ through the estrogen-ER-LSD1 axis and dGTP and other dNTPs adjacent to the replication forks are at high risk of oxidation by $\mathrm{H}_{2} \mathrm{O}_{2}$ or hydroxy radicals, generating increased levels of 8-oxo-dGTP. Transgenic expression of hMTH1 efficiently hydrolyzes 8-oxo-dGTP to monophosphate, minimizing 8-oxoG accumulation in nuclear DNA.

Single deficiency of OGG1 did not suppress the age-dependent decline of locomotor activity in middle-aged female mice, indicating that there may only be a small amount of 8-oxoG forming opposite cytosine in DNA by direct oxidation of guanine (Nishioka et al., 1999; Nakabeppu et al., 2017). In contrast, MTH1/OGG1-double deficiency abolished both 8-oxo-dGTP hydrolysis and 8-oxoG excision repair once incorporated into DNA, increasing its accumulation in nuclear DNA in proliferating neural stem/progenitor cells, particularly in female mice.

In conclusion, sexual dimorphism in spontaneous locomotor activity may be at least partially attributed to 8-oxo-dGTP generated in neural stem/progenitor cells through the estrogen-ER-LSD1 axis. Moreover, MTH1 and OGG1 together efficiently minimize 8-oxoG accumulation in the nuclear DNA, maintaining brain architecture during aging.

\section{Declarations of interest}

None.

\section{Funding}

This work was partly supported by grants from the Japan Society for the Promotion of Science (grant numbers 22221004, 15K15085, 17H01391 to Y.N.).

\section{Acknowledgements}

We thank Edanz Group (www.edanzediting.com/ac) for editing a draft of this manuscript. We also thank S. Kitamura, K. Nakabeppu, T. Kuwano and T. Koizumi for their technical assistance.

\section{Appendix A. The Peer Review Overview and Supplementary data}

The Peer Review Overview and Supplementary data associated with this article can be found in the online version, at doi: https://doi.org/ 10.1016/j.pneurobio.2019.04.002.

\section{References}

Bevins, R.A., Besheer, J., 2006. Object recognition in rats and mice: a one-trial non matching-to-sample learning task to study' recognition memory' Nat. Protoc. 1, $1306-1311$.

Braun, S.M., Jessberger, S., 2014. Adult neurogenesis: mechanisms and functional significance. Development 141, 1983-1986.

Cardozo-Pelaez, F., Sanchez-Contreras, M., Nevin, A.B., 2012. Ogg1 null mice exhibit ageassociated loss of the nigrostriatal pathway and increased sensitivity to MPTP. Neurochem. Int. 61, 721-730.

Chikama, K., Yamada, H., Tsukamoto, T., Kajitani, K., Nakabeppu, Y., Uchimura, N. 2017. Chronic atypical antipsychotics, but not haloperidol, increase neurogenesis in the hippocampus of adult mouse. Brain Res. 1676, 77-82.

Choleris, E., Galea, L.A.M., Sohrabji, F., Frick, K.M., 2018. Sex differences in the brain: implications for behavioral and biomedical research. Neurosci. Biobehav. Rev. 85, 126-145.

Cobb, C.A., Cole, M.P., 2015. Oxidative and nitrative stress in neurodegeneration. 
Neurobiol. Dis. 84, 4-21.

Coppede, F., Migliore, L., 2015. DNA damage in neurodegenerative diseases. Mutat. Res. 776, 84-97.

Dasuri, K., Zhang, L., Keller, J.N., 2013. Oxidative stress, neurodegeneration, and the balance of protein degradation and protein synthesis. Free Radic. Biol. Med. 62, 170-185.

Dayer, A.G., Cleaver, K.M., Abouantoun, T., Cameron, H.A., 2005. New GABAergic interneurons in the adult neocortex and striatum are generated from different precursors. J. Cell Biol. 168, 415-427.

De Luca, G., Russo, M.T., Degan, P., Tiveron, C., Zijno, A., Meccia, E., Ventura, I., Mattei, E., Nakabeppu, Y., Crescenzi, M., et al., 2008. A role for oxidized DNA precursors in Huntington's disease-like striatal neurodegeneration. PLoS Genet. 4, e1000266.

De Luca, G., Ventura, I., Sanghez, V., Russo, M., Ajmone-Cat, M., Cacci, E., Martire, A., Popoli, P., Falcone, G., Michelini, F., et al., 2013. Prolonged lifespan with enhanced exploratory behavior in mice overexpressing the oxidized nucleoside triphosphatase hMTH1. Aging Cell 12, 695-705.

De Marchis, S., Fasolo, A., Puche, A.C., 2004. Subventricular zone-derived neuronal progenitors migrate into the subcortical forebrain of postnatal mice. J. Comp. Neurol. 476, 290-300.

Diaz, J., Levesque, D., Lammers, C.H., Griffon, N., Martres, M.P., Schwartz, J.C., Sokoloff, P., 1995. Phenotypical characterization of neurons expressing the dopamine D3 receptor in the rat brain. Neuroscience 65, 731-745.

Duarte-Guterman, P., Yagi, S., Chow, C., Galea, L.A., 2015. Hippocampal learning, memory, and neurogenesis: effects of sex and estrogens across the lifespan in adults. Horm. Behav. 74, 37-52.

Ernst, A., Alkass, K., Bernard, S., Salehpour, M., Perl, S., Tisdale, J., Possnert, G., Druid, H., Frisén, J., 2014. Neurogenesis in the striatum of the adult human brain. Cell 156, 1072-1083.

Farinetti, A., Tomasi, S., Foglio, B., Ferraris, A., Ponti, G., Gotti, S., Peretto, P., Panzica, G.C., 2015. Testosterone and estradiol differentially affect cell proliferation in the subventricular zone of young adult gonadectomized male and female rats. Neuroscience 286, 162-170.

Fiszbein, A., Kornblihtt, A.R., 2016. Histone methylation, alternative splicing and neuronal differentiation. Neurogenesis 3, e1204844.

Forneris, F., Binda, C., Vanoni, M.A., Mattevi, A., Battaglioli, E., 2005. Histone demethylation catalysed by LSD1 is a flavin-dependent oxidative process. FEBS Lett. 579, 2203-2207.

Forneris, F., Battaglioli, E., Mattevi, A., Binda, C., 2009. New roles of flavoproteins in molecular cell biology: histone demethylase LSD1 and chromatin. FEBS J. 276, 4304-4312.

Fukae, J., Takanashi, M., Kubo, S., Nishioka, K., Nakabeppu, Y., Mori, H., Mizuno, Y., Hattori, N., 2005. Expression of 8-oxoguanine DNA glycosylase (OGG1) in Parkinson's disease and related neurodegenerative disorders. Acta Neuropathol. 109, $256-262$.

Furuta, A., Iida, T., Nakabeppu, Y., Iwaki, T., 2001. Expression of hMTH1 in the hippocampi of control and Alzheimer's disease. Neuroreport 12, 2895-2899.

Gkikas, D., Tsampoula, M., Politis, P.K., 2017. Nuclear receptors in neural stem/progenitor cell homeostasis. Cell. Mol. Life Sci. 74, 4097-4120.

Hall, A.K., 2012. Development of the nervous system. In: Brady, S., Siegel, G. (Eds.), Basic. Neurochemistry. Academic Press, Waltham, MA, USA, pp. 533-545.

Heberden, C., 2017. Sex steroids and neurogenesis. Biochem. Pharmacol. 141, 56-62.

Hirano, K., Namihira, M., 2016. New insight into LSD1 function in human cortical neurogenesis. Neurogenesis 3, e1249195.

Hope, B.T., Nye, H.E., Kelz, M.B., Self, D.W., Iadarola, M.J., Nakabeppu, Y., Duman, R.S., Nestler, E.J., 1994. Induction of a long-lasting AP-1 complex composed of altered Foslike proteins in brain by chronic cocaine and other chronic treatments. Neuron 13, 1235-1244.

Hu, X.T., Koeltzow, T.E., Cooper, D.C., Robertson, G.S., White, F.J., Vezina, P., 2002 Repeated ventral tegmental area amphetamine administration alters dopamine D1 receptor signaling in the nucleus accumbens. Synapse 45, 159-170.

Iida, T., Furuta, A., Nishioka, K., Nakabeppu, Y., Iwaki, T., 2002. Expression of 8-oxoguanine DNA glycosylase is reduced and associated with neurofibrillary tangles in Alzheimer's disease brain. Acta Neuropathol. 103, 20-25.

Inta, D., Alfonso, J., von Engelhardt, J., Kreuzberg, M.M., Meyer, A.H., van Hooft, J.A., Monyer, H., 2008. Neurogenesis and widespread forebrain migration of distinct GABAergic neurons from the postnatal subventricular zone. Proc. Natl. Acad. Sci. U. S. A. 105, 20994-20999.

Kajitani, K., Yamaguchi, H., Dan, Y., Furuichi, M., Kang, D., Nakabeppu, Y., 2006. MTH1, an oxidized purine nucleoside triphosphatase, suppresses the accumulation of oxidative damage of nucleic acids in the hippocampal microglia during kainate-induced excitotoxicity. J. Neurosci. 26, 1688-1698.

Kajitani, K., Nomaru, H., Ifuku, M., Yutsudo, N., Dan, Y., Miura, T., Tsuchimoto, D., Sakumi, K., Kadoya, T., Horie, H., et al., 2009. Galectin-1 promotes basal and kainateinduced proliferation of neural progenitors in the dentate gyrus of adult mouse hippocampus. Cell Death Differ. 16, 417-427.

Kang, D., Takeshige, K., Sekiguchi, M., Singh, K., 1999. Introduction. In: Singh, K. (Ed.), Mitochondrial DNA Mutations in Aging, Disease and Cancer. Springer-Verlag, Berlin, pp. $1-15$.

Kempermann, G., Gage, F.H., Aigner, L., Song, H., Curtis, M.A., Thuret, S., Kuhn, H.G., Jessberger, S., Frankland, P.W., Cameron, H.A., et al., 2018. Human adult neurogenesis: evidence and remaining questions. Cell Stem Cell 23, 25-30.

Kikuchi, H., Furuta, A., Nishioka, K., Suzuki, S.O., Nakabeppu, Y., Iwaki, T., 2002. Impairment of mitochondrial DNA repair enzymes against accumulation of 8-oxoguanine in the spinal motor neurons of amyotrophic lateral sclerosis. Acta Neuropathol. 103, 408-414.

Klinker, F., Kohnemann, K., Paulus, W., Liebetanz, D., 2017. Dopamine D3 receptor status modulates sexual dimorphism in voluntary wheel running behavior in mice. Behav. Brain Res. 333, 235-241.

Koeltzow, T.E., Xu, M., Cooper, D.C., Hu, X.T., Tonegawa, S., Wolf, M.E., White, F.J., 1998. Alterations in dopamine release but not dopamine autoreceptor function in dopamine D3 receptor mutant mice. J. Neurosci. 18, 2231-2238.

Kohnomi, S., Konishi, S., 2015. Multiple actions of a D(3) dopamine receptor agonist, PD128907, on GABAergic inhibitory transmission between medium spiny neurons in mouse nucleus accumbens shell. Neurosci. Lett. 600, 17-21.

Laine, M.A., Sokolowska, E., Dudek, M., Callan, S.A., Hyytia, P., Hovatta, I., 2017. Brain activation induced by chronic psychosocial stress in mice. Sci. Rep. 7, 15061.

Laurent, B., Ruitu, L., Murn, J., Hempel, K., Ferrao, R., Xiang, Y., Liu, S., Garcia, B.A., Wu, H., Wu, F., et al., 2015. A specific LSD1/KDM1A isoform regulates neuronal differentiation through H3K9 demethylation. Mol. Cell 57, 957-970.

Le Moine, C., Bloch, B., 1996. Expression of the D3 dopamine receptor in peptidergic neurons of the nucleus accumbens: comparison with the D1 and D2 dopamine receptors. Neuroscience 73, 131-143.

Leon, J., Sakumi, K., Castillo, E., Sheng, Z., Oka, S., Nakabeppu, Y., 2016. 8-Oxoguanine accumulation in mitochondrial DNA causes mitochondrial dysfunction and impairs neuritogenesis in cultured adult mouse cortical neurons under oxidative conditions. Sci. Rep. 6, 22086.

Li, Y., Kuzhikandathil, E.V., 2012. Molecular characterization of individual D3 dopamine receptor-expressing cells isolated from multiple brain regions of a novel mouse model. Brain Struct. Funct. 217, 809-833.

Liu, D., Croteau, D.L., Souza-Pinto, N., Pitta, M., Tian, J., Wu, C., Jiang, H., Mustafa, K. Keijzers, G., Bohr, V.A., et al., 2011. Evidence that OGG1 glycosylase protects neurons against oxidative DNA damage and cell death under ischemic conditions. J. Cereb. Blood Flow Metab. 31, 680-692.

MacKenna, M.C., Dienel, G.A., Sonnewald, U., Waagepetersen, H.S., Schousboe, A., 2012. Energy Metaboilsm of the Brain. In: Brady, S., Siegel, G. (Eds.), Basic Neurochemistry. Academic Press, Waltham, MA, USA, pp. 200-231.

Mahmoud, R., Wainwright, S.R., Galea, L.A., 2016. Sex hormones and adult hippocampal neurogenesis: regulation, implications, and potential mechanisms. Front. Neuroendocrinol. 41, 129-152.

Moller, P., Lohr, M., Folkmann, J.K., Mikkelsen, L., Loft, S., 2010. Aging and oxidatively damaged nuclear DNA in animal organs. Free Radic. Biol. Med. 48, 1275-1285.

Murakami, Y., Ikeda, Y., Yoshida, N., Notomi, S., Hisatomi, T., Oka, S., De Luca, G., Yonemitsu, Y., Bignami, M., Nakabeppu, Y., et al., 2012. MutT homolog-1 attenuates oxidative DNA damage and delays photoreceptor cell death in inherited retinal degeneration. Am. J. Pathol. 181, 1378-1386.

Nakabeppu, Y., 2017. In: Wilson III, D.M. (Ed.), The Base Excision Repair Pathway: Molecular Mechanisms and Role in Disease Development and Therapeutic Design. World Scientific Publishing Co., Pte. Ltd, Singapore, pp. 523-556.

Nakabeppu, Y., Ohta, E., Abolhassani, N., 2017. MTH1 as a nucleotide pool sanitizing enzyme: friend or foe? Free Radic. Biol. Med. 107, 151-158.

Nestler, E.J., 2013. Cellular basis of memory for addiction. Dialogues Clin. Neurosci. 15, 431-443.

Nie, B., Gan, W., Shi, F., Hu, G.X., Chen, L.G., Hayakawa, H., Sekiguchi, M., Cai, J.P., 2013. Age-dependent accumulation of 8-oxoguanine in the DNA and RNA in various rat tissues. Oxid. Med. Cell. Longev. 2013, 303181.

Nishioka, K., Ohtsubo, T., Oda, H., Fujiwara, T., Kang, D., Sugimachi, K., Nakabeppu, Y., 1999. Expression and differential intracellular localization of two major forms of human 8-oxoguanine DNA glycosylase encoded by alternatively spliced OGG1 mRNAs. Mol. Biol. Cell 10, 1637-1652.

Nunnari, J., Suomalainen, A., 2012. Mitochondria: in sickness and in health. Cell 148, 1145-1159.

Ohno, M., Sakumi, K., Fukumura, R., Furuichi, M., Iwasaki, Y., Hokama, M., Ikemura, T., Tsuzuki, T., Gondo, Y., Nakabeppu, Y., 2014. 8-Oxoguanine causes spontaneous de novo germline mutations in mice. Sci. Rep. 4, 4689.

Oka, S., Ohno, M., Tsuchimoto, D., Sakumi, K., Furuichi, M., Nakabeppu, Y., 2008. Two distinct pathways of cell death triggered by oxidative damage to nuclear and mitochondrial DNAs. EMBO J. 27, 421-432.

Okada, M., Makino, A., Nakajima, M., Okuyama, S., Furukawa, S., Furukawa, Y., 2010. Estrogen stimulates proliferation and differentiation of neural stem/progenitor cells through different signal transduction pathways. Int. J. Mol. Sci. 11, 4114-4123.

Olsen, C.M., 2011. Natural rewards, neuroplasticity, and non-drug addictions. Neuropharmacology 61, 1109-1122.

Pawluski, J.L., Brummelte, S., Barha, C.K., Crozier, T.M., Galea, L.A., 2009. Effects of steroid hormones on neurogenesis in the hippocampus of the adult female rodent during the estrous cycle, pregnancy, lactation and aging. Front. Neuroendocrinol. 30, 343-357.

Perillo, B., Ombra, M.N., Bertoni, A., Cuozzo, C., Sacchetti, S., Sasso, A., Chiariotti, L., Malorni, A., Abbondanza, C., Avvedimento, E.V., 2008. DNA oxidation as triggered by H3K9me2 demethylation drives estrogen-induced gene expression. Science 319, 202-206.

Ponti, G., Farinetti, A., Marraudino, M., Panzica, G., Gotti, S., 2018. Sex steroids and adult neurogenesis in the ventricular-subventricular zone. Front. Endocrinol. 9, 156.

Sakumi, K., Tominaga, Y., Furuichi, M., Xu, P., Tsuzuki, T., Sekiguchi, M., Nakabeppu, Y., 2003. Ogg1 knockout-associated lung tumorigenesis and its suppression by Mth1 gene disruption. Cancer Res. 63, 902-905.

Saravia, F., Revsin, Y., Lux-Lantos, V., Beauquis, J., Homo-Delarche, F., De Nicola, A.F., 2004. Oestradiol restores cell proliferation in dentate gyrus and subventricular zone of streptozotocin-diabetic mice. J. Neuroendocrinol. 16, 704-710.

Sattarova, E.A., Sinitsyna, O.I., Vasyunina, E.A., Duzhak, A.B., Kolosova, N.G., Zharkov, D.O., Nevinsky, G.A., 2013. Age-dependent guanine oxidation in DNA of different brain regions of Wistar rats and prematurely aging OXYS rats. Biochim. Biophys. Acta $1830,3542-3552$. 
Seifermann, M., Epe, B., 2017. Oxidatively generated base modifications in DNA: not only carcinogenic risk factor but also regulatory mark? Free Radic. Biol. Med. 107, 258-265.

Shapiro, L.A., Ng, K., Zhou, Q.Y., Ribak, C.E., 2009. Subventricular zone-derived, newly generated neurons populate several olfactory and limbic forebrain regions. Epilepsy Behav. 14 (Suppl. 1), 74-80.

Sheng, Z., Oka, S., Tsuchimoto, D., Abolhassani, N., Nomaru, H., Sakumi, K., Yamada, H., Nakabeppu, Y., 2012. 8-Oxoguanine causes neurodegeneration during MUTYHmediated DNA base excision repair. J. Clin. Invest. 122, 4344-4361.

Shimura-Miura, H., Hattori, N., Kang, D., Miyako, K., Nakabeppu, Y., Mizuno, Y., 1999. Increased 8-oxo-dGTPase in the mitochondria of substantia nigral neurons in Parkinson's disease. Ann. Neurol. 46, 920-924.

Sokoloff, P., Le Foll, B., 2017. The dopamine D3 receptor, a quarter century later. Eur. J. Neurosci. 45, 2-19.

Song, X.N., Zhang, L.Q., Liu, D.G., Lin, J., Zheng, J.D., Dai, D.P., Hei, A.L., Hayakawa, H., Sekiguchi, M., Cai, J.P., 2011. Oxidative damage to RNA and expression patterns of MTH1 in the hippocampi of senescence-accelerated SAMP8 mice and Alzheimer's disease patients. Neurochem. Res. 36, 1558-1565.

Sun, G., Alzayady, K., Stewart, R., Ye, P., Yang, S., Li, W., Shi, Y., 2010. Histone demethylase LSD1 regulates neural stem cell proliferation. Mol. Cell. Biol. 30, 1997-2005.

Swain, U., Rao, K.S., 2012. Age-dependent decline of DNA base excision repair activity in rat cortical neurons. Mech. Ageing Dev. 133, 186-194.
Tian, F., Tong, T.J., Zhang, Z.Y., McNutt, M.A., Liu, X.W., 2009. Age-dependent downregulation of mitochondrial 8-oxoguanine DNA glycosylase in SAM-P/8 mouse brain and its effect on brain aging. Rejuvenation Res. 12, 209-215.

Tsuzuki, T., Egashira, A., Igarashi, H., Iwakuma, T., Nakatsuru, Y., Tominaga, Y., Kawate, H., Nakao, K., Nakamura, K., Ide, F., et al., 2001. Spontaneous tumorigenesis in mice defective in the MTH1 gene encoding 8-oxo-dGTPase. Proc. Natl. Acad. Sci. U. S. A. 98, 11456-11461.

Ventura, I., Russo, M.T., De Nuccio, C., De Luca, G., Degan, P., Bernardo, A., Visentin, S., Minghetti, L., Bignami, M., 2013. hMTH1 expression protects mitochondria from Huntington's disease-like impairment. Neurobiol. Dis. 49, 148-158.

Wenzel, J.M., Rauscher, N.A., Cheer, J.F., Oleson, E.B., 2015. A role for phasic dopamine release within the nucleus accumbens in encoding aversion: a review of the neurochemical literature. ACS Chem. Neurosci. 6, 16-26.

Werme, M., Messer, C., Olson, L., Gilden, L., Thoren, P., Nestler, E.J., Brene, S., 2002. $\triangle$ FosB regulates wheel running. J. Neurosci. 22, 8133-8138.

Xu, M., Koeltzow, T.E., Santiago, G.T., Moratalla, R., Cooper, D.C., Hu, X.T., White, N.M., Graybiel, A.M., White, F.J., Tonegawa, S., 1997. Dopamine D3 receptor mutant mice exhibit increased behavioral sensitivity to concurrent stimulation of D1 and D2 receptors. Neuron 19, 837-848.

Yamaguchi, H., Kajitani, K., Dan, Y., Furuichi, M., Ohno, M., Sakumi, K., Kang, D., Nakabeppu, Y., 2006. MTH1, an oxidized purine nucleoside triphosphatase, protects the dopamine neurons from oxidative damage in nucleic acids caused by 1-methyl-4phenyl-1,2,3,6-tetrahydropyridine. Cell Death Differ. 13, 551-563. 